\title{
Large lakes harbor streamlined free-living nitrifiers
}

5 Justin C. Podowskia, Sara F. Pavera, Ryan J. Newton ${ }^{b}$, Maureen L. Coleman ${ }^{\text {a\# }}$

a Department of the Geophysical Sciences, University of Chicago, Chicago, Illinois, USA

b School of Freshwater Sciences, University of Wisconsin Milwaukee, Milwaukee, Wisconsin, USA

Corresponding author: Department of the Geophysical Sciences Hinds Laboratory 5734 S. Ellis Ave.

Telephone: (773) 702-8352

22 Running title: Nitrifiers across the Laurentian Great Lakes 


\section{Abstract}

25 Microbial nitrification is a critical process governing nitrogen availability in aquatic systems and

26 provides energy for aphotic carbon fixation. Nitrifiers are phylogenetically and physiologically

27 diverse, but the factors controlling this diversity, and its biogeochemical implications, are poorly

28 understood, particularly in freshwater systems. Here, we characterized the taxonomic, genomic,

29 and metabolic diversity of free-living nitrifiers across Earth's largest freshwater system, the

30 Laurentian Great Lakes. Surprisingly, ammonia oxidizing Bacteria (AOB) related to Nitrosospira

31 dominated over ammonia oxidizing Archaea (AOA) at most stations, even in oligotrophic lakes

32 with extremely low substrate concentrations. Nitrite oxidizing Bacteria (NOB) Ca. Nitrotoga and

33 Nitrospira each dominated a subset of stations, even switching within a lake. Among four

34 ecotypes of Nitrosospira we identified, one encodes proteorhodopsin, which could enhance

35 survival of this AOB in transparent, low nutrient lakes. Genome reconstructions for free-living

36 AOA, AOB, and NOB indicate small genomes across all taxa and diverse adaptations to

37 sunlight and oxidative stress. Our findings expand the known functional diversity of nitrifiers and

38 provide the first integrated picture of freshwater nitrifier genomics and ecology. As lakes

39 worldwide undergo rapid environmental change, understanding the relationship between

40 microbial biodiversity and nitrogen cycling is essential for predicting future ecosystem health

41 and services. 


\section{Introduction}

The oxidation of ammonia to nitrate powers the growth of nitrifying microorganisms and represents a critical flux in the global nitrogen cycle. In aquatic systems, microbial nitrification of ammonia released from sinking organic matter produces nitrate, which can then be removed

47 from the system by denitrification (1). As chemolithoautotrophs, nitrifiers are also a major source 48 of dark carbon fixation (2), which may contribute significant organic carbon to the microbial food 49 web of the ocean's interior (3-5) and of deep freshwater lakes (6).

Microbial nitrifiers encompass wide diversity in phylogeny, physiology, and ecology, and understanding the drivers and consequences of this diversity across ecosystems is a

52 fundamental challenge. Ammonia-oxidizing Archaea (AOA) in the phylum Thaumarchaeota

53 dominate the mesopelagic oceans $(7,8)$, likely due to their high affinity for ammonia $(9,10)$ and

54 streamlined genomes (11). In freshwater systems, AOA have been found to dominate

55 oligotrophic lakes, while ammonia-oxidizing Bacteria (AOB) affiliated with the

Nitrosomonadaceae (Betaproteobacteria) dominate more eutrophic systems (12-17).

57 Complicating this picture, however, there is considerable genomic and physiological variation

58 within each group. Some lineages, such as the thaumarchaeal Nitrosopelagicus (11) and

59 bacterial Nitrosomonas cluster $6 a(18,19)$, seem to be more specialized for nutrient scarcity than

60 other related lineages. Within the AOA, there are also distinct ecotypes that appear to segregate

61 with depth in the water column, in both marine $(8,20)$ and freshwater systems $(12)$. In

62 freshwaters especially - which are poorly characterized compared to the oceans - it remains

63 difficult to predict which ammonia-oxidizing taxa are likely to dominate in a given system.

64 For aquatic nitrite oxidizers, which span the phyla Nitrospira, Nitrospinae, and

65 Proteobacteria, niche differentiation is even less clear. The oceans are dominated by

66 exclusively marine lineages $(2,21,22)$, consistent with ancient salinity-driven divergence.

67 Cultivated strains of NOB show variation in substrate affinity and physiology $(21,23,24)$, but the

68 phylogenetic conservation of these traits, and their influence on environmental distributions, are 
poorly understood. Moreover, recent studies have discovered that NOB are capable of alternative energy metabolisms $(25,26)$ and can access nitrogen from cyanate and urea $(27-$

71 29), expanding their ecological potential. In freshwater systems, the NOB Ca. Nitrotoga

72 (Betaproteobacteria) was only recently discovered to be widespread (30), and the diversity of

73 this genus and factors favoring its success are unknown.

Here, we use the Laurentian Great Lakes as a model system to examine niche partitioning among planktonic freshwater nitrifiers. The Great Lakes hold $20 \%$ of Earth's surface freshwater and more than half of this volume receives little to no light ( $<1 \%$ surface irradiance).

77 This system, while hydrologically connected, spans strong trophic and chemical gradients:

78 ultraoligotrophic Lake Superior supports rates of primary production and nitrification comparable

79 to the ocean gyres $(31,32)$, while Lake Erie supports greater production (33) and more than 70 -

80 fold higher nitrification rate (34). Between these extremes, Lake Ontario has low ambient

81 ammonium concentrations like Lake Superior (35) but nitrification rates up to four times higher

82 (36). While previous studies reported that AOA and AOB dominate Lakes Superior and Erie,

83 respectively $(16,32)$, recent community profiling has revealed broader diversity in both

84 ammonia-oxidizing and nitrite-oxidizing lineages (37-39). We sought to link taxonomic,

85 genomic, and metabolic diversity of nitrifiers with the varied biogeochemistry of the Great Lakes,

86 using genome reconstructions and abundance profiling. Our results uncover novel lineages and

87 metabolic capabilities and provide the first large-scale assessment of freshwater nitrifier

88 genomics.

89 Materials and Methods

90 Sample collection

91 Water samples were collected from the Laurentian Great Lakes aboard the R/V Lake

92 Guardian, during the biannual Water Quality Surveys conducted by the U.S. EPA Great Lakes

93 National Program Office (40). Data presented here were collected in April and August 2012. 
94 Samples were collected using a CTD rosette sampler (Sea-Bird Scientific) at the surface $(2 \mathrm{~m})$,

95 deep chlorophyll maximum (if present), the mid-hypolimnion, and near the bottom of the water

96 column (10 $\mathrm{m}$ above the lake bottom at most stations, $1 \mathrm{~m}$ above bottom at shallow stations).

97 For each sample, 5-8L of water was pre-filtered through a GF/A glass fiber filter (Whatman

98 1820-047; nominal pore size $1.6 \mu \mathrm{m}$ ) to exclude eukaryotic phytoplankton and particle

99 associated microbes, and cells were collected on $0.22 \mu \mathrm{m}$ Sterivex filters (Millipore

100 SVGP01050). Filters were stored at $-80^{\circ} \mathrm{C}$. For dissolved nutrient analysis, $0.22 \mu \mathrm{m}$ filtrate was

101 collected in $125 \mathrm{ml}$ acid-clean HDPE bottles (Nalgene) and stored at $-20^{\circ} \mathrm{C}$. Samples for single

102 cell amplified genomes (SAG) were collected in August 2014. For each sample, $1 \mathrm{ml}$ of raw

103 water was incubated with $100 \mu \mathrm{l}$ of glycerol-TE buffer $(20 \mathrm{ml}$ 100X TE pH $8+100 \mathrm{ml}$ glycerol +

$10460 \mathrm{ml}$ water; final concentration after sample addition is $10 \mathrm{mM}$ Tris, $1 \mathrm{mM}$ EDTA, $5 \%$ glycerol)

105 for 10 minutes in the dark, then flash frozen in liquid nitrogen and stored at $-80^{\circ} \mathrm{C}$ until

106 processing.

107

108

109

110

\section{Physicochemical data}

CTD profiles, water chemistry and chlorophyll-a data were collected by the U.S. EPA according to standard protocols (41) and retrieved from the Great Lakes Environmental Database (https://cdx.epa.gov/) for 2012 and 2013. In addition, we measured dissolved nitrogen species from August 2013 samples. Ammonium concentrations were measured using the OPA method in a 96-well plate (42). Nitrate and nitrite concentrations were measured using the Greiss reaction method in a 96-well plate (43).

\section{S rRNA analysis}

The full 16S rRNA amplicon dataset was described by Paver and colleagues (37). Here we focus on data from the V4-V5 region (primers 515F-Y, 926R; ref. 44), collected in 2012 in tandem with metagenome samples from select stations. We classified sequences using the Silva v. 132 database (45) and the wang method (46) as implemented by mothur (47). 
119 Sequences classified to each detected family of nitrifiers (ammonia oxidizer families

120 Nitrosomonadaceae and Nitrosopumilaceae; nitrite oxidizer families Gallionellaceae and

121 Nitrospiraceae) with a mothur-assigned confidence score above 90 were delineated into

122 taxonomic units using minimum entropy decomposition with a minimum substantive abundance

123 of $10(48)$.

\section{Metagenome and single-cell genome analysis}

One station per lake in Superior, Michigan, Huron, and Ontario, and two stations in Erie, were selected for metagenome sequencing. DNA was extracted using a modified

127 phenol:chloroform extraction protocol (37) and libraries prepared according to the Illumina

128 TruSeq protocol. Samples from spring 2012 were sequenced at the Joint Genome Institute using Illumina HiSeq (2x150bp). Samples from summer 2012 were sequenced at the University of Chicago Functional Genomics Core Facility using Illumina HiSeq 2500 (2x250bp). Separate assemblies of quality filtered reads were carried out for each metagenome using metaSPAdes 3.1.11 (49). Detailed QC, assembly, contig binning, and annotation are described in Supplementary Methods.

To confirm the presence of proteorhodopsin, we analyzed a single cell amplified genome from Nitrosospira collected from Lake Michigan and sequenced by the Joint Genome Institute. 


\section{Results}

\section{Niche partitioning of nitrifiers across the Great Lakes}

To map free-living (here defined as cells that pass through a $1.6 \mu \mathrm{m}$ filter) nitrifiers across the Great Lakes, we searched our recent 16S rRNA datasets for known nitrifying taxa (37). We detected putative AOB in the genus Nitrosospira (Betaproteobacteria) and AOA similar to Nitrosoarchaeum, along with putative NOB in the genera Ca. Nitrotoga (Betaproteobacteria) and Nitrospira (Nitrospirae). We did not detect 16S rRNA amplicons from Nitrosococcus,

Nitrococcus, Nitrospina or Nitrobacter. The relative abundance of nitrifiers was negatively correlated with photosynthetically active radiation (PAR; Spearman's rho $=-0.89, p<2.2 e-16$ ) and reached a maximum below the depth of $1 \%$ PAR in each lake, up to $20 \%$ of amplicon sequences (Fig S1a). The relative abundances of ammonia- and nitrite-oxidizing taxa were strongly correlated (Spearman's rho $=0.918, p<2.2 e-16$; Fig S1b). Free-living nitrifiers were rare $(<0.1 \%$ relative abundance $)$ in bottom water samples from the southern basin of Huron (HU15M) and western basin of Erie (HU91M); these two stations are the shallowest in our dataset and have relatively high light penetration to the bottom ( 1\% PAR). Chlorophyll-a concentration was also negatively correlated with the relative abundance of nitrifiers (Spearman's rho $=-0.677, p<1.7 e-7 ;$ Fig S1c). These findings are consistent with previous work demonstrating photoinhibition of nitrification (51-54), as well as potential competition with phototrophs for ammonium (55).

The taxonomic assemblage of nitrifiers, along with nitrogen availability, differed across lakes and even across stations within a lake (Fig 1, Tables S1-S3). AOB (Nitrosomonadaceae) were observed across all lakes. In contrast, AOA (Nitrosoarchaeum) sequences only exceeded $0.5 \%$ relative abundance at the three deepest stations (SU08M, MI41M, ON55M) where the ratio of AOB:AOA ranged from 10:1 to 1:3 (Table S1). A single dominant oligotype accounted for more than $85 \%$ of Nitrosoarchaeum sequences in all samples, while four major oligotypes of 
Nitrosomonadaceae were observed (data not shown). We found pronounced shifts in the dominant NOB across stations (Fig 1), and all stations except those in Lake Ontario showed

171 strong dominance (greater than ten-fold) of either Ca. Nitrotoga or Nitrospira. Nitrospira was the

172 only nitrite oxidizer detected in Superior and the dominant nitrite oxidizer in parts of Michigan

173 (MI41M, MI18M). By contrast, Ca. Nitrotoga was the only nitrite oxidizer observed in Erie and

174 Huron and the dominant nitrite oxidizer at the shallowest station in Michigan (MI27M). In all but

175 one sample, a single dominant oligotype of Ca. Nitrotoga and Nitrospira accounted for $>74 \%$

176 and $>84 \%$ of sequences from each taxon, respectively.

\section{Ecotypic variation in abundant streamlined Nitrosospira}

178 We reconstructed 15 genomes of the AOB Nitrosospira, substantially expanding genome

179 descriptions for this genus (56-58). Based on a phylogenomic tree, free-living Great Lakes

180 Nitrosospira fall into two major clades, both of which are distinct from published species; each of

181 these clades also includes MAGs recovered from lakes Biwa and Baikal, suggesting novel

182 globally distributed freshwater lineages (Fig S2). One clade, which we call NspGL1, has a

183 reduced genome (average $1.4 \mathrm{Mb}$ ) and low $\mathrm{G}+\mathrm{C}$ content (41\%) (Fig 2, Table S4), typical of

184 streamlined genomes (59). The second clade was resolved into three subclades (denoted

185 NspGL2a, 2b, and 3; Fig S2) based on phylogeny and average nucleotide identity (ANI), all with

186 small genome sizes of 1.5-1.8 Mb and $50 \% \mathrm{G}+\mathrm{C}$ content (Fig 2, Table S4). Based on short read

187 mapping, these subclades are ecologically distinct: NspGL1 and NspGL2b -- with the smallest

188 genomes -- are the dominant AOB in the upper oligotrophic lakes, while NspGL2a is only

189 abundant in Ontario and NspGL3 is only abundant in Erie (Fig 2). Hereafter we refer to these

190 subclades as ecotypes due to their phylogenetic and ecological separation.

191 We compared the genomes of our Great Lakes Nitrosospira to 87 reference AOB

192 genomes belonging to the family Nitrosomonadaceae, revealing distinctive patterns of gene

193 content. Great Lakes Nitrosospira genomes encode fewer two-component signal transduction 
systems, transposases, motility genes, pilus and secretion genes, and defense-related genes, and their complement of transporters is distinct from most reference genomes (Table S5). They also lack functions related to biofilm formation such as polysaccharide matrix production (e.g. pel genes) and extracellular protein targeting (exosortase and PEP-CTERM motifs). These features are in sharp contrast to Nitrosospira isolates from soil $(56,58)$ and to oligotrophic Nitrosomonas isolates (60) and are consistent with a passive planktonic lifestyle in extremely 200 low-nutrient systems.

We next compared metabolic potential among Great Lakes AOB ecotypes to understand 202 their ecological preferences for upper lakes (NspGL1, NspGL2b), Ontario (NspGL2a), and Erie 203 (NspGL3). Surprisingly, all seven NspGL1 MAGs contain a cluster of genes encoding 204 proteorhodopsin and retinal biosynthesis, including 15,15'-Beta-carotene dioxygenase (b/h), 205 lycopene cyclase (crtY), phytoene dehydrogenase (crtl), phytoene synthase (crtB), and GGPP synthase (crtE) (Fig 3a). We also identified proteorhodopsin in a single cell amplified genome (SAG) representing NspGL1 from Lake Michigan (Fig 3a), demonstrating that it is not an artifact of metagenome assembly. To our knowledge, this is the first example of a nitrifier with proteorhodopsin. All NspGL1 proteorhodopsins share residues H95, D127 and E138 along with a short beta-turn (G111-P116) between helices B and C, which are characteristic features of

211 proteorhodopsin as distinct from sensory and other rhodopsins (61), and the presence of

212 leucine at position 135 suggests green light tuning (62) (Fig 3b). All of the genes in this module

213 have highest similarity to homologs from Polynucleobacter, but are flanked by

214 Nitrosomonadaceae-like genes, suggesting recent horizontal gene transfer (Fig 3a). The

215 predicted NspGL1 proteorhodopsins cluster with Polynucleobacter, Methylopumilus, and other

216 freshwater Betaproteobacteria in Supercluster III as defined by MicRhoDE (63) (Fig S3). We

217 compared the homologous genome region in two highly similar MAGs from Lakes Biwa and

218 Baikal (Fig S2); these contigs lack the proteorhodopsin module but appear to flank a variable

219 region where the contig assembly ends (Fig S4). A proteorhodopsin photosystem could support 
220 survival of NspGL1 in the presence of sunlight, which has been shown to inhibit ammonia

221 oxidation $(51,64)$. In the upper lakes where NspGL1 is abundant, light penetration is high well

222 below the thermocline in stratified periods (65), and deep water taxa are seasonally advected to

223 the surface by water column mixing (37). In addition to proteorhodopsin, NspGL1 - but not the

224 other three ecotypes of Great Lakes Nitrosospira - encode a class I cyclopyrimidine dimer

225 photolyase, which uses light energy to repair UV-induced DNA damage, and the catalase-

226 peroxidase $k a t G$, suggesting that the NspGL1 ecotype is adapted to relatively shallow depths in

227 the water column (Fig 2).

228 Great Lakes Nitrosospira carry a reduced, ecotype-specific complement of nitrogen

229 metabolism genes compared to reference AOB (Fig 2; Table S5). All are presumed to have the

230 core ammonia oxidation enzymes ammonia monooxygenase and hydroxylamine

231 dehydrogenase; these genes were assembled and binned as expected in some MAGs and

232 were manually identified on short unbinned contigs in other cases. Surprisingly, all Great Lakes

233 Nitrosospira lack the copper protein nitrosocyanin, whose precise function is unknown but so far

234 has been found in all AOB except one member of the $N$. oligotropha clade (60). The lack of

235 nitrosocyanin extends beyond the Great Lakes MAGs to closely related freshwater and marine

236 strains, along with five more members of the N. oligotropha clade (Fig S2); its absence may be

237 related to the divergence of these clades. Only NspGL1 and NspGL2b encode NO-forming

238 nitrite reductase (NirK), which confers nitrite tolerance (66); this result is surprising given that

239 these two clades dominate the upper lakes where productivity and reduced $\mathrm{N}$ are lowest. None

240 of the Great Lakes MAGs encode NO reductase (NorCBQD), and NspGL1 lacks cytochrome

241 P460 family proteins; these genomic patterns may influence $\mathrm{N}_{2} \mathrm{O}$ emissions across the Great

242 Lakes. Nitrogen acquisition is also distinct among Great Lakes AOB: NspGL1 lacks an apparent

243 ammonium transporter, but encodes urease structural and accessory genes (ureABCEFG) and

244 a high-affinity urea transporter ( $u r t A B C D E$ ). Further, all Great Lakes ecotypes encode a high-

245 affinity amino acid transporter (livFGHM) and a secreted non-specific nuclease; these genes are 
246 rare $(<5 \%)$ in reference genomes and could supply reduced nitrogen and/or organic carbon.

247 Finally, NspGL1 and NspGL3 have genes for producing cyanophycin, an intracellular storage

248 compound for nitrogen $(58,67)$. Together, the minimal and distinctive gene complements

249 present in Great Lakes Nitrosospira illustrate the variability and adaptability of AOB gene

250 content across habitats.

251 As with nitrogen metabolism, carbon metabolism is also distinct between Great Lakes

252 and reference AOB, and among Great Lakes ecotypes (Fig 2; Table S5). Unlike most reference

253 AOB, Great Lakes Nitrosospira lack two key enzymes of the oxidative pentose phosphate

254 pathway, glucose-6-phosphate dehydrogenase and 6-phosphogluconate dehydrogenase. All

255 ecotypes except Erie-specific NspGL3 also lack genes for glycogen synthesis and degradation.

256 These findings suggest continuous autotrophy, rather than "feast or famine" dynamics of carbon

257 storage and utilization, or diel periodicity as in photoautotrophs. The key enzyme for carbon

258 fixation, RuBisCO, has evolved several kinetically distinct forms whose distribution likely reflects

259 ecological pressures (68). NspGL1 and NspGL3 both contain Form IA RuBisCO, while

260 NspGL2a and NspGL2b contain Form IC RuBisCO $(68,69)$ (Fig 2). NspGL1 genomes also

261 possess an alpha carboxysome-like cso operon, similar to Nitrosomonas eutropha C91 (69),

262 though our draft assembly lacks the expected carbonic anhydrase (csoS3/csoSCA).

263 Carboxysome-associated RuBisCO may allow NspGL1, the ecotype most strongly adapted to

264 energy and nutrient limitation, to more efficiently fix $\mathrm{CO}_{2}$ by minimizing the wasteful oxygenation

265 reaction and reducing the cellular nitrogen allocation to RuBisCO (68). The ranges of kinetic

266 properties observed in other autotrophs for Form IAq (found in NspGL3) and Form IC (found in

267 NspGL2a and NspGL2b) overlap, and therefore more work is needed to understand the fitness

268 advantages, if any, that this RuBisCO diversity confers on Great Lakes nitrifiers.

269 Streamlined freshwater Thaumarchaeota 
We reconstructed three similar genomes (>99\% ANI) of Nitrosoarchaeum (NarchGL; Fig

271 S5, Fig S6, Table S4) from three separate samples (two from Superior, one from Ontario),

272 consistent with our low observed 16S rRNA diversity for Thaumarchaeota. These NarchGL

273 genomes are very similar ( 99\% ANI) to two genomes reconstructed from Lake Baikal, located

274 thousands of kilometers away (70). Their next closest relatives are also from freshwater

275 environments, and phylogenetic clustering suggests that salinity is an important driver of

276 divergence throughout the Nitrosopumilaceae (Fig S5). Using our reconstructed genomes as

277 probes for metagenomic read recruitment, NarchGL were detected in Superior, Michigan, and

278 Ontario; they represented roughly one-third of ammonia oxidizers in the mid-hypolimnion of

279 station SU08M, reaching relative abundance of approximately $0.5 \%$ (Fig 2 ).

NarchGL share nearly $90 \%$ of their predicted proteins with close relatives including Ca.

281 Nitrosoarchaeum limnia; at the same time, they show distinctive patterns in gene content that

282 pinpoint the key selective pressures of deep lakes (Fig 2, Table S6). All three NarchGL

283 genomes encode urease and a urea transporter, implicating urea as a vital source of nitrogen

284 for energy and/or biosynthesis. Consistent with phosphorus scarcity in much of the Great Lakes

285 (71), NarchGL encode high affinity transport systems for phosphate and potentially

286 phosphonates, though we did not identify a phosphonate lyase. In addition to both CRISPR/Cas

287 enzymes cas1 and cas4, NarchGL genomes contain several phage proteins, suggesting viral

288 infection and integration events may be common. DNA photolyases, which have been found in

289 epipelagic clades of marine Thaumarchaeota (72-74), are present in all low salinity

290 Nitrosoarchaeum including NarchGL, suggesting NarchGL are exposed to sunlight due to high

291 water clarity (65) and/or annual mixing in the Great Lakes. NarchGL also lack the common

292 tRNA modification 4-thiouridylation (indicated by IscS K04487 and Thil-NFACT PF02568-

293 PF18297; ref. 75); we propose that the absence of this modification, which is susceptible to

294 near-UV radiation (75), is also related to sunlight exposure. 
While aquatic AOA are typically adapted to oligotrophic conditions, NarchGL appear especially streamlined. Their genomes reveal striking reduction in environmental sensing, response, and regulatory functions, relative to other Nitrosoarchaeum and Nitrosopumilaceae

298 (Table S6). NarchGL encode fewer variants of the general archaeal transcription factors, TATA 299 binding protein (TBPs, PF00352) and transcription factor B (TFBs, PF00382 and PF08271),

300 combinations of which influence differential gene expression (76). NarchGL also encode fewer

301 two-component systems that transmit environmental signals to control gene expression or 302 protein activity (domains: cache PF02743, HAMP PF00672, His kinase A PF00512, receiver

303 PF00072). Further, they are depleted in ArsR family transcription factors (PF01022), P-II

304 proteins for regulation of nitrogen metabolism (PF00543), and other potential regulatory domains (CBS PF00571, USP PF00582). This extremely limited regulatory capacity in NarchGL

306 stands in sharp contrast to closely related Ca. N. limnia, but instead parallels the oceanic

307 minimalist Ca. Nitrosopelagicus brevis (11) (Table S6).

308

309

\section{Expanded diversity of Ca. Nitrotoga with reduced genomes}

Despite the broad distribution of $\mathrm{Ca}$. Nitrotoga in freshwater systems and beyond, only six genomes are available, derived from rivers heavily impacted by urban and agricultural influence, a wastewater treatment plant, and coastal sediment $(30,77,78)$. Hence the metabolic and phylogenetic diversity of this group is virtually unexplored. We reconstructed six new MAGs of $\mathrm{Ca}$. Nitrotoga, which form two clusters with $>99 \%$ ANI within each cluster and $\sim 97 \%$ ANI between clusters (NtogaGL1a and NtogaGL1b; Fig S2). These new Ca. Nitrotoga MAGs are far smaller than published genomes (1.5 Mb compared to 2.6-3.0 Mb; Fig 4, Table S4), lacking functions such as motility and chemotaxis, pilus biogenesis, and DNA repair (mutLS) (Table S7). Great Lakes Ca. Nitrotoga also encode markedly fewer two-component systems for sensing and responding to environmental cues, defense-related genes (restriction-modification, toxin-antitoxin, and Crispr-Cas systems), transposases, and efflux transporters (Table S7). 
320 While incomplete assembly of hypervariable genome regions may explain some of these

321 absences, the overall genome properties are consistent with a relatively stable low-nutrient 322 environment and planktonic lifestyle.

The reduced genomes of NtogaGL1a/b help clarify core features of the genus Nitrotoga,

324 along with accessory functions that may enable local adaptation in specific populations. To date,

325 sequenced Ca. Nitrotoga including NtogaGL1a/b encode similar electron transport pathways,

326 including NADH dehydrogenase-Complex I, succinate dehydrogenase-Complex II, and

327 Alternative Complex III, along with high-affinity cbb3-type cytochrome oxidases suggesting

328 adaptation to low oxygen conditions. They also share the Calvin cycle for carbon fixation, a

329 complete TCA cycle, and an evolutionarily distinct nitrite oxidoreductase (NXR) from other NOB

$330(30,77,78)$. All Ca. Nitrotoga to date also share transporters for amino acids and peptides,

331 potential sources of C and/or N. Ca. Nitrotoga can also potentially access reduced sulfur

332 compounds for energy via sulfite dehydrogenase, suggesting metabolic flexibility beyond nitrite

333 oxidation.

334 Beyond these similarities, the small genomes of NtogaGL1a/b are distinct from

335 previously described Ca. Nitrotoga in many ways. NtogaGL1a/b lack NiFe hydrogenase to use

336 hydrogen as an energy source. They also lack nitrogen metabolism functions including

337 assimilatory nitrite reductase (nirBD), nitrite reductase to NO (nirK), and nitric oxide reductase

338 (norQD). Based on gene content, NtogaGL1a/b appear unable to use hexoses like glucose,

339 since they lack the glycolytic enzyme phosphofructokinase and the Entner-Doudoroff pathway,

340 similar to Nitrobacter winogradskyi (79). Consistent with this, they also lack genes for storage

341 and breakdown of glycogen (Table S7). All but one of the NtogaGL1a/1b genomes encode

342 cyanate lyase (cynS), which is found in other NOB but no Ca. Nitrotoga to date $(27,80,81)$. The

343 cynS gene, adjacent to glnK-amtB for ammonium sensing and transport, likely functions in $\mathrm{N}$

344 assimilation, as recently described for Nitrospinae (22). While cyanase has been shown to

345 mediate reciprocal feeding between some NOB and ammonia oxidizers (27), this interaction is 
unlikely in the free-living (<1.6um) size-fraction and dilute environment sampled here. Notably, cyanase from NtogaGL1a/1b, along with predicted Nitrospirae proteins from Lake Baikal and soil, form a distinct phylogenetic cluster from most nitrifier cyanase proteins observed to date

349 (Fig S7).

The two ANI-based clusters we detected, NtogaGL1a and NtogaGL1b, appear to be phylogenetically and ecologically distinct ecotypes. Based on short-read mapping, NtogaGL1b dominates Erie, while NtogaGL1a dominates all other Ca. Nitrotoga-containing samples (Fig 4). We found several metabolic genes that differentiate the two ecotypes. ER-specific NtogaGL1b

354 genomes share a region encoding thiosulfate dehydrogenase $(t s d A)$, cytochromes, transport of

355 sulfur-containing compounds, lactate dehydrogenase (Idh), a two-component system, and a

356 Crp-family transcription factor (Fig S8). This region may be involved in oxidizing thiosulfate as

357 an energy source, and sensing and responding to redox changes that accompany seasonal

358 hypoxia in Lake Erie. The corresponding region in NtogaGL1a encodes an integrase and 359 photolyase, consistent with greater DNA photodamage in the more transparent waters of

360 Michigan, Huron, and Ontario where NtogaGL1a is abundant. NtogaGL1a also lacks superoxide 361 oxidase $(c y b B)$ found in NtogaGL1b and reference strains, suggesting these two ecotypes 362 experience differential oxidative stress.

\section{Great Lakes Nitrospira reveal adaptations to sunlit oxic environment}

We reconstructed six closely related genomes of Nitrospira ( 99\% ANI; Fig S9, Table S4), representing the predominant NOB throughout Lake Superior and in parts of Michigan, Ontario, and Huron (Fig. 4; Table S1). These genomes, which we refer to as NspiraGL, fall

367 within lineage II (Fig S9), which is broadly distributed across soil, freshwater, and engineered

368 habitats (21); however, genome analyses to date have focused on strains from wastewater and 369 engineered systems, leaving major blind spots. NspiraGL share core features of Nitrospira 370 metabolism, including a periplasmic-facing NXR that is advantageous under substrate-limiting 
371 conditions, multiple cytochrome bd-like oxidases, and the reverse TCA cycle for carbon fixation

372 (80). However, as with Ca. Nitrotoga, the Nitrospira genomes we reconstructed in the Great

373 Lakes are markedly smaller ( 1.8 Mb) than published reference genomes (Fig. 4; Table S4),

374 with reduced capacity for environmental sensing, transport, defense, and transposition, and a

375 lack of pilus or flagellar motility (Table S8). NspiraGL encode just five sigma factors, compared

376 to 18 in Nitrospira moscoviensis, consistent with genome streamlining theory (59). Further,

377 NspiraGL genomes encode a single NXR, while N. moscoviensis carries five copies that are

378 differentially regulated $(29,82)$. NspiraGL also lack the glnE gene for glutamine synthetase (GS)

379 adenylyltransferase, suggesting that GS activity is not repressed by this mechanism. Together,

380 these features suggest limited regulatory and ecological flexibility, consistent with a relatively

381 constant, oligotrophic environment.

access diverse nitrogen sources (Fig. 4, Table S8). We predict that NspiraGL are unable to

grow on hydrogen or formate as alternative energy sources $(25,29)$, as they lack NiFe-

hydogenase and formate dehydrogenase. The glycolysis and oxidative TCA cycles appear to be incomplete, lacking phosphofructokinase and citrate synthase, respectively; this suggests a

387 limited capacity for organic carbon utilization. Regarding nitrogen metabolism, NspiraGL lack nirK, encoding NO-forming nitrite reductase, but maintain nitric oxide reductase (norQD), implying that cellular NO is formed by other mechanisms. To obtain nitrogen for biosynthesis, 390 NspiraGL encode a high-affinity nitrate/nitrite/cyanate transporter ( $n r t A B C$ ), assimilatory nitrite 391 reductase (nirA), and cyanase (cynS), along with two amt family ammonium transporters.

392 Although none of the NspiraGL MAGs include urease (ureCBA), one does contain urease 393 accessory proteins (ureEFGD) and two contain a urea transporter ( $u r t A B C D$ ), suggesting 394 incomplete assembly of the urea utilization pathway. As with $\mathrm{Ca}$. Nitrotoga, we suggest that 395 cyanase, along with urease where present, functions in nitrogen assimilation rather than cross396 feeding, given the dilute environment and free-living planktonic cells. 
Beyond energy, carbon, and nitrogen metabolism, we discovered striking differences between NspiraGL and reference Nitrospira related to DNA repair. NspiraGL encode two additional photolyase-related proteins, along with a class I cyclopyrimidine dimer (CPD)

400 photolyase found in most reference Nitrospira (Fig 5, Fig S10). Photolyases use blue light

401 energy to repair DNA lesions caused by UV radiation (83). The two additional genes in

402 NspiraGL are adjacent and share best hits with Betaproteobacteria, suggesting recent

403 horizontal transfer (Fig 5). One likely encodes an FeS-BCP photolyase, which repairs (6-4)

404 dipyrimidine lesions $(84,85)$. The other shares an FAD-binding domain with photolyases but the

405 C-terminal region has no recognizable domains (Fig 5b). This protein is widespread in aquatic

406 bacteria and has not been functionally characterized, though an actinobacterial homolog was

407 suggested to be involved in light sensing and regulation (86). Beyond photolyases, NspiraGL

408 also encode uracil-DNA glycosylase (UNG), which removes misincorporated uracil from DNA.

409 Uracil results from deamination of cytosine, which can occur spontaneously or be induced by

410 NO (87). In addition to the photolyases and UNG that repair DNA lesions, NspiraGL encode

411 translesion DNA polymerase $\mathrm{V}(u m u C D)$ which enables replication to proceed past lesions.

412 Together, these genes indicate that Nitrospira in the Great Lakes experience significant DNA

413 damage, including UV-induced damage that also requires light for the repair process, in

414 hypolimnion waters with high transparency (65) and/or during seasonal mixing.

415 Other major differences between NspiraGL and reference Nitrospira are related to

416 reactive oxygen species (ROS) (Table S8). Surprisingly, despite their oxic habitat, NspiraGL

417 lack superoxide dismutase (SOD), monofunctional catalase (katE), classic regulators of

418 oxidative stress response (oxyR and perR), and bacterioferritin, which limits the Fenton reaction

419 by sequestering free iron. However, all six NspiraGL MAGs, but few reference genomes (7\% of

420 75), have recently acquired bifunctional catalase-peroxidase katG; interestingly we also

421 observed katG in Great Lakes Ca. Nitrotoga and Nitrosospira (Fig 2, Fig 4). The absence of

422 SOD suggests that NspiraGL does not produce damaging levels of endogenous superoxide, 
423 perhaps because NspiraGL lack the major respiratory and non-respiratory flavoproteins that

424 produce ROS in other SOD-containing Nitrospira (88). Unlike superoxide, $\mathrm{H}_{2} \mathrm{O}_{2}$ can cross

425 membranes, and is known to be produced by both photooxidation of dissolved organic matter

426 and dark heterotrophic activity (89). The lakes where NspiraGL dominate have high water clarity

427 (65) and low productivity, consistent with abiotic photochemistry as the primary source of

428 exogenous ROS; this stress may have selected for katG as a defense, though without the

429 canonical oxyR regulation. The absence of bacterioferritin could be related to iron limitation (71).

430 NspiraGL also lack cytochrome $c$ peroxidase, which is found in 70 of 75 reference genomes;

431 this protein is proposed to function in anaerobic respiration of $\mathrm{H}_{2} \mathrm{O}_{2}(90)$ and therefore its

432 absence in NspiraGL is consistent with a constant oxic environment. Together, these results

433 indicate that Nitrospira in the Great Lakes face distinct ROS pressures that have shaped their

434 gene content.

Discussion

The Laurentian Great Lakes harbor nitrifiers that are phylogenetically related, but

438 markedly different in genome size and functional capacity, from their well-studied relatives

439 inhabiting wastewater systems, soils, and even other freshwater systems. By examining the

440 entire nitrifier assemblage at once, we detected common features across taxa that illuminate the

441 selective pressures faced by microbes in deep lakes. All the lineages we describe show small

442 genome sizes (1.3-1.8 Mb), reduced capacity for environmental sensing and response, and

443 adaptation to a passive (i.e. non-motile) planktonic lifestyle, expanding the paradigm of

444 streamlining observed for oceanic AOA (11) to AOB, Nitrospira, and Ca. Nitrotoga in

445 oligotrophic freshwaters. Within the cosmopolitan Nitrosospira, we found ecotypes with a

446 gradient of genome reduction that maps onto their habitats' trophic gradient: from NspGL1 (1.4

$447 \mathrm{Mb}$, low GC, upper lakes) to NspGL2b (1.5 Mb, upper lakes) to NspGL2a (1.6 Mb, Ontario) to

448 NspGL3 (1.8 Mb, Erie) (Fig 2). The thaumarchaeal NarchGL have markedly reduced regulatory 
capacity like the open ocean strain Nitrosopelagicus brevis (11). The NOB NspiraGL have genomes $50-60 \%$ smaller than described Nitrospira and dominate, along with the AOB NspGL1

451 and the AOA NarchGL, the deeper more oligotrophic basins, while Ca. Nitrotoga favor shallower

452 more productive basins. The emergence of Erie-specific ecotypes of both Nitrosospira

453 (NspGL3) and Ca. Nitrotoga (NtogaGL1b) demonstrates how distinct this habitat is compared to 454 the other lakes.

Nitrifiers inhabiting the transparent waters of the upper Great Lakes show distinctive

456 adaptations to light including diverse photolyases, ROS detoxification, and even

457 proteorhodopsin. This discovery is surprising, given that nitrifiers are rare in the surface mixed

458 layer of the Great Lakes (Fig. S1) and that photoinhibition of ammonia oxidation and nitrifier

459 growth is well documented $(51-54,64)$. We propose that proteorhodopsin could be used to

460 augment energy metabolism when ammonia oxidation is photoinhibited. Water clarity has

461 increased over the past several decades in Lakes Michigan and Huron, now surpassing that of

462 Lake Superior (65). High light penetration along with seasonal mixing likely exposes deep water

463 cells to damaging levels of light and oxidative stress. Future cultivation and physiological studies

464 will document photoinhibition and potential phototrophy in Great Lakes nitriifiers.

The capacity for nitrification is found across multiple phyla, and our work unveils new

466 clues to understanding the ecological and evolutionary potential of these diverse lineages. This

467 collective nitrifier diversity undoubtedly influences the cycling of carbon and nitrogen across this

468 ecosystem, and future work will explore the differential contributions to nitrification by the distinct

469 lineages we described here. Understanding what controls the diversity of nitrifiers and other key

470 functional groups, and the consequences of this diversity for biogeochemistry, are essential for

471 forecasting the effects of rapid environmental change across the large lakes of the world (e.g.

472 ref. 91) and predicting impacts on the critical ecosystem services they provide (92). 


\section{References}

475 1. Canfield DE, Glazer AN, Falkowski PG. The evolution and future of Earth's nitrogen cycle. Science 2010; 330:192-6.

2. Pachiadaki MG, Sintes E, Bergauer K, Brown JM, Record NR, Swan BK, et al. Major role of nitrite-oxidizing bacteria in dark ocean carbon fixation. Science 2017; 358:1046-51.

3. Reinthaler T, van Aken HM, Herndl GJ. Major contribution of autotrophy to microbial carbon cycling in the deep North Atlantic's interior. Deep Sea Res Part II: Topical Studies in Oceanography 2010; 57:1572-80.

4. Swan BK, Martinez-Garcia M, Preston CM, Sczyrba A, Woyke T, Lamy D, et al. Potential for chemolithoautotrophy among ubiquitous bacteria lineages in the dark ocean. Science 2011; 333:1296-300.

5. Baltar F, Herndl GJ. Ideas and perspectives: Is dark carbon fixation relevant for oceanic primary production estimates? Biogeosciences 2019; 16:3793-9.

6. Callieri C, Coci M, Eckert EM, Salcher MM, Bertoni R. Archaea and Bacteria in deep lake hypolimnion: in situ dark inorganic carbon uptake. J Limnol 2014; 73:31-38.

7. Wuchter C, Abbas B, Coolen MJL, Herfort L, van Bleijswijk J, Timmers P, et al. Archaeal nitrification in the ocean. Proc Natl Acad Sci USA 2006; 103:12317-22.

8. Francis CA, Roberts KJ, Beman JM, Santoro AE, Oakley BB. Ubiquity and diversity of ammonia-oxidizing archaea in water columns and sediments of the ocean. Proc Natl Acad Sci USA 2005; 102:14683-8.

9. Schleper C. Ammonia oxidation: different niches for bacteria and archaea? ISME J 2010; 4:1092-4.

10. Martens-Habbena W, Berube PM, Urakawa H, de la Torre JR, Stahl DA. Ammonia oxidation kinetics determine niche separation of nitrifying Archaea and Bacteria. Nature 2009; 461:976-9.

11. Santoro AE, Dupont CL, Richter RA, Craig MT, Carini P, Mcllvin MR, et al. Genomic and proteomic characterization of "Candidatus Nitrosopelagicus brevis": An ammonia-oxidizing archaeon from the open ocean. Proc Natl Acad Sci USA 2015; 112:1173-8.

12. Auguet J-C, Triadó-Margarit X, Nomokonova N, Camarero L, Casamayor EO. Vertical segregation and phylogenetic characterization of ammonia-oxidizing Archaea in a deep oligotrophic lake. ISME J 2012; 6:1786-97.

13. Herber J, Klotz F, Frommeyer B, Weis S, Straile D, Kolar A, et al. A single Thaumarchaeon drives nitrification in deep oligotrophic Lake Constance. Environ Microbiol 2020; 22:21228.

14. Urbach E, Vergin KL, Young L, Morse A, Larson GL, Giovannoni SJ. Unusual bacterioplankton community structure in ultra-oligotrophic Crater Lake. Limnol Oceanogr 2001; 46:557-72.

15. Okazaki Y, Fujinaga S, Tanaka A, Kohzu A, Oyagi H, Nakano S. Ubiquity and quantitative significance of bacterioplankton lineages inhabiting the oxygenated hypolimnion of deep freshwater lakes. ISME J 2017; 11:2279-93.

16. Mukherjee M, Ray A, Post AF, McKay RM, Bullerjahn GS. Identification, enumeration and diversity of nitrifying planktonic archaea and bacteria in trophic end members of the Laurentian Great Lakes. J Great Lakes Res 2016; 42:39-49.

17. Hugoni M, Etien S, Bourges A, Lepère C, Domaizon I, Mallet C, et al. Dynamics of ammonia-oxidizing Archaea and Bacteria in contrasted freshwater ecosystems. Res Microbiol 2013; 164:360-70.

18. Bollmann A, Bar-Gilissen M-J, Laanbroek HJ. Growth at low ammonium concentrations and starvation response as potential factors involved in niche differentiation among ammonia-oxidizing bacteria. Appl Environ Microbiol 2002; 68:4751-7.

19. Sedlacek CJ, McGowan B, Suwa Y, Sayavedra-Soto L, Laanbroek HJ, Stein LY, et al. A 
524

525

526

527

528

529

530

531

532

533

534

535

536

537

538

539

540

541

542

543

544

545

546

547

548

549

550

551

552

553

554

555

556

557

558

559

560

561

562

563

564

565

566

567

568

569

570

571

572

573

574 physiological and genomic comparison of Nitrosomonas cluster 6a and 7 ammoniaoxidizing bacteria. Microb Ecol 2019; 78:985-94.

20. Beman JM, Popp BN, Francis CA. Molecular and biogeochemical evidence for ammonia oxidation by marine Crenarchaeota in the Gulf of California. ISME J 2008; 2:429-41.

21. Daims $\mathrm{H}$, Lücker $\mathrm{S}$, Wagner $\mathrm{M}$. A new perspective on microbes formerly known as nitriteoxidizing bacteria. Trends Microbiol 2016; 24:699-712.

22. Kitzinger K, Marchant HK, Bristow LA, Herbold CW, Padilla CC, Kidane AT, et al. Single cell analyses reveal contrasting life strategies of the two main nitrifiers in the ocean. Nature Comm 2020; 11:767.

23. Nowka B, Daims H, Spieck E. Comparison of oxidation kinetics of nitrite-oxidizing bacteria: nitrite availability as a key factor in niche differentiation. Appl Environ Microbiol 2015; 81:745-53.

24. Wegen S, Nowka B, Spieck E. Low temperature and neutral pH define "Candidatus Nitrotoga sp." as a competitive nitrite oxidizer in coculture with Nitrospira defluvii. Appl Environ Microbiol 2019; 85:e02569-18.

25. Koch H, Galushko A, Albertsen M, Schintlmeister A, Gruber-Dorninger C, Lucker S, et al. Growth of nitrite-oxidizing bacteria by aerobic hydrogen oxidation. Science 2014; 345:1052-4.

26. Füssel J, Lücker S, Yilmaz P, Nowka B, van Kessel MAHJ, Bourceau P, et al. Adaptability as the key to success for the ubiquitous marine nitrite oxidizer Nitrococcus. Science Advances 2017; 3:e1700807.

27. Palatinszky M, Herbold C, Jehmlich N, Pogoda M, Han P, von Bergen M, et al. Cyanate as an energy source for nitrifiers. Nature 2015; 524:105-8.

28. Kitzinger K, Padilla CC, Marchant HK, Hach PF, Herbold CW, Kidane AT, et al. Cyanate and urea are substrates for nitrification by Thaumarchaeota in the marine environment. Nat Microbiol 2019; 4:234.

29. Koch H, Lücker S, Albertsen M, Kitzinger K, Herbold C, Spieck E, et al. Expanded metabolic versatility of ubiquitous nitrite-oxidizing bacteria from the genus Nitrospira. Proc Natl Acad Sci USA 2015; 112:11371-6.

30. Boddicker AM, Mosier AC. Genomic profiling of four cultivated Candidatus Nitrotoga spp. predicts broad metabolic potential and environmental distribution. ISME J 2018; 12:286482.

31. Sterner RW. In situ-measured primary production in Lake Superior. J Great Lakes Res 2010; 36:139-49.

32. Small GE, Bullerjahn GS, Sterner RW, Beall BFN, Brovold S, Finlay JC, et al. Rates and controls of nitrification in a large oligotrophic lake. Limnol Oceanogr 2013; 58:276-86.

33. Vollenweider RA, Munawar M, Stadelmann P. A comparative review of phytoplankton and primary production in the Laurentian Great Lakes. J Fish Res Bd Can 1974; 31:739-62.

34. Clevinger CC, Heath RT, Bade DL. Oxygen use by nitrification in the hypolimnion and sediments of Lake Erie. J Great Lakes Res 2014; 40:202-7.

35. Neilson MA, Stevens RJJ. Spatial heterogeneity of nutrients and organic matter in Lake Ontario. Can J Fish Aquat Sci 1987; 44:2192-203.

36. Lean DRS, Knowles R. Nitrogen transformations in Lake Ontario. Can J Fish Aquat Sci $1987 ; 44: 2133-43$.

37. Paver SF, Newton RJ, Coleman ML. Microbial communities of the Laurentian Great Lakes reflect connectivity and local biogeochemistry. Environ Microbiol 2020; 22:433-46.

38. Rozmarynowycz MJ, Beall BFN, Bullerjahn GS, Small GE, Sterner RW, Brovold SS, et al. Transitions in microbial communities along a $1600 \mathrm{~km}$ freshwater trophic gradient. J Great Lakes Res 2019; 45:263-76.

39. Fujimoto M, Cavaletto J, Liebig JR, McCarthy A, Vanderploeg HA, Denef VJ. Spatiotemporal distribution of bacterioplankton functional groups along a freshwater 
575

576

577

578

579

580

581

582

583

584

585

586

587

588

589

590

591

592

593

594

595

596

597

598

599

600

601

602

603

604

605

606

607

608

609

610

611

612

613

614

615

616

617

618

619

620

621

622

623

624

625

estuary to pelagic gradient in Lake Michigan. J Great Lakes Res 2016; 42:1036-48.

40. Barbiero RP, Lesht BM, Hinchey EK, Nettesheim TG. A brief history of the U.S. EPA Great Lakes National Program Office's water quality survey. J Great Lakes Res 2018; 44:53946.

41. US Environmental Protection Agency. Sampling and analytical procedures for GLNPO's open lake water quality survey of the Great Lakes. Great Lakes National Program Office, Illinois, USA; 2003.

42. Holmes RM, Aminot A, Kérouel R, Hooker BA, Peterson BJ. A simple and precise method for measuring ammonium in marine and freshwater ecosystems. Can J Fish Aquat Sci 1999; 56:1801-8.

43. Miranda KM, Espey MG, Wink DA. A rapid, simple spectrophotometric method for simultaneous detection of nitrate and nitrite. Nitric Oxide 2001; 5:62-71.

44. Parada AE, Needham DM, Fuhrman JA. Every base matters: assessing small subunit rRNA primers for marine microbiomes with mock communities, time series and global field samples. Environ Microbiol 2016; 18:1403-14.

45. Quast C, Pruesse E, Yilmaz P, Gerken J, Schweer T, Yarza P, et al. The SILVA ribosomal RNA gene database project: improved data processing and web-based tools. Nucleic Acids Res 2013; 41:D590-6.

46. Wang Q, Garrity GM, Tiedje JM, Cole JR. Naïve Bayesian classifier for rapid assignment of rRNA sequences into the new bacterial taxonomy. Appl Environ Microbiol 2007; 73:5261-7.

47. Kozich JJ, Westcott SL, Baxter NT, Highlander SK, Schloss PD. Development of a dualindex sequencing strategy and curation pipeline for analyzing amplicon sequence data on the MiSeq Illumina sequencing platform. Appl Environ Microbiol 2013; 79:5112-20.

48. Eren AM, Maignien L, Sul WJ, Murphy LG, Grim SL, Morrison HG, et al. Oligotyping: differentiating between closely related microbial taxa using 16S rRNA gene data. Methods Ecol Evol 2013; 4:1111-9.

49. Nurk S, Meleshko D, Korobeynikov A, Pevzner PA. metaSPAdes: a new versatile metagenomic assembler. Genome Res 2017; 27:824-34.

50. Bankevich A, Nurk S, Antipov D, Gurevich AA, Dvorkin M, Kulikov AS, et al. SPAdes: a new genome assembly algorithm and its applications to single-cell sequencing. $J$ Comput Biol 2012; 19:455-77.

51. Hooper AB, Terry KR. Photoinactivation of ammonia oxidation in Nitrosomonas. J Bacteriol 1974; 119:899-906.

52. Horrigan SG, Springer AL. Oceanic and estuarine ammonium oxidation: Effects of light. Limnol Oceanogr 1990; 35:479-82.

53. Guerrero M, Jones R. Photoinhibition of marine nitrifying bacteria. I. Wavelengthdependent response. Mar Ecol Prog Ser 1996; 141:183-92.

54. Merbt SN, Stahl DA, Casamayor EO, Martí E, Nicol GW, Prosser JI. Differential photoinhibition of bacterial and archaeal ammonia oxidation. FEMS Microbiol Lett 2012; 327:41-6.

55. Smith JM, Chavez FP, Francis CA. Ammonium uptake by phytoplankton regulates nitrification in the sunlit ocean. PLOS ONE 2014; 9:e108173.

56. Rice MC, Norton JM, Valois F, Bollmann A, Bottomley PJ, Klotz MG, et al. Complete genome of Nitrosospira briensis C-128, an ammonia-oxidizing bacterium from agricultural soil. Stand Genomic Sci 2016; 11:46.

57. Garcia JC, Urakawa H, Le VQ, Stein LY, Klotz MG, Nielsen JL. Draft genome sequence of Nitrosospira sp. Strain APG3, a psychrotolerant ammonia-oxidizing bacterium isolated from sandy lake sediment. Genome Announcements 2013; 1:e00930-13.

58. Norton JM, Klotz MG, Stein LY, Arp DJ, Bottomley PJ, Chain PSG, et al. Complete genome sequence of Nitrosospira multiformis, an ammonia-oxidizing bacterium from the 
626

627

628

629

630

631

632

633

634

635

636

637

638

639

640

641

642

643

644

645

646

647

648

649

650

651

652

653

654

655

656

657

658

659

660

661

662

663

664

665

666

667

668

669

670

671

672

673

674

675

676

soil environment. Appl Environ Microbiol 2008; 74:3559-72.

59. Giovannoni SJ, Cameron Thrash J, Temperton B. Implications of streamlining theory for microbial ecology. ISME J 2014; 8:1553-65.

60. Bollmann A, Sedlacek CJ, Norton J, Laanbroek HJ, Suwa Y, Stein LY, et al. Complete genome sequence of Nitrosomonas sp. Is79, an ammonia oxidizing bacterium adapted to low ammonium concentrations. Stand Genomic Sci 2013; 7:469-82.

61. Reckel S, Gottstein D, Stehle J, Löhr F, Verhoefen M-K, Takeda M, et al. Solution NMR structure of proteorhodopsin. Angewandte Chemie 2011; 50:11942-6.

62. Kralj JM, Bergo VB, Amsden JJ, Spudich EN, Spudich JL, Rothschild KJ. Protonation state of Glu142 differs in the green- and blue-absorbing variants of proteorhodopsin. Biochem 2008; 47:3447-53.

63. Boeuf D, Audic S, Brillet-Guéguen L, Caron C, Jeanthon C. MicRhoDE: a curated database for the analysis of microbial rhodopsin diversity and evolution. Database 2015; bav080.

64. Hyman MR, Arp DJ. ${ }^{14} \mathrm{C}_{2} \mathrm{H}_{2-}$ and ${ }^{14} \mathrm{CO}_{2}$-labeling studies of the de novo synthesis of polypeptides by Nitrosomonas europaea during recovery from acetylene and light inactivation of ammonia monooxygenase. J Biol Chem 1992; 267:1534-45.

65. Yousef F, Shuchman R, Sayers M, Fahnenstiel G, Henareh A. Water clarity of the Upper Great Lakes: Tracking changes between 1998-2012. J Great Lakes Res 2017; 43:239-47.

66. Beaumont HJE, Hommes NG, Sayavedra-Soto LA, Arp DJ, Arciero DM, Hooper AB, et al. Nitrite reductase of Nitrosomonas europaea is not essential for production of gaseous nitrogen oxides and confers tolerance to nitrite. J Bacteriol 2002; 184:2557-60.

67. Watzer B, Forchhammer K. Cyanophycin synthesis optimizes nitrogen utilization in the unicellular cyanobacterium Synechocystis sp. strain PCC 6803. Appl Environ Microbiol 2018; 84:e01298-18.

68. Badger MR, Bek EJ. Multiple Rubisco forms in proteobacteria: their functional significance in relation to $\mathrm{CO}_{2}$ acquisition by the CBB cycle. $J$ Exp Bot 2008; 59:1525-41.

69. Rae BD, Long BM, Badger MR, Price GD. Functions, compositions, and evolution of the two types of carboxysomes: polyhedral microcompartments that facilitate $\mathrm{CO}_{2}$ fixation in cyanobacteria and some Proteobacteria. Microbiol Mol Biol Rev 2013; 77:357-79.

70. Cabello-Yeves PJ, Zemskaya TI, Rosselli R, Coutinho FH, Zakharenko AS, Blinov VV, et al. Genomes of novel microbial lineages assembled from the sub-ice waters of Lake Baikal. Appl Environ Microbiol 2018; 84: e02132-17.

71. Sterner RW, Smutka TM, McKay RML, Xiaoming Q, Brown ET, Sherrell RM. Phosphorus and trace metal limitation of algae and bacteria in Lake Superior. Limnol Oceanogr 2004; 49:495-507.

72. Bayer B, Vojvoda J, Offre P, Alves RJE, Elisabeth NH, Garcia JA, et al. Physiological and genomic characterization of two novel marine thaumarchaeal strains indicates niche differentiation. ISME J 2016; 10:1051-63.

73. Luo H, Tolar BB, Swan BK, Zhang CL, Stepanauskas R, Ann Moran M, et al. Single-cell genomics shedding light on marine Thaumarchaeota diversification. ISME J 2014; 8:7326.

74. Ahlgren NA, Chen Y, Needham DM, Parada AE, Sachdeva R, Trinh V, et al. Genome and epigenome of a novel marine Thaumarchaeota strain suggest viral infection, phosphorothioation DNA modification and multiple restriction systems. Environ Microbiol 2017; 19:2434-52.

75. Ryals J, Hsu RY, Lipsett MN, Bremer $\mathrm{H}$. Isolation of single-site Escherichia coli mutants deficient in thiamine and 4-thiouridine syntheses: identification of a nuvC mutant. $J$ Bacteriol 1982; 151:899-904.

76. Karr EA. Transcription Regulation in the Third Domain. In: Sariaslani S, Gadd GM (eds). Advances in Applied Microbiology. Academic Press, 2014, pp. 101-33. 
677

678

679

680

681

682

683

684

685

686

687

688

689

690

691

692

693

694

695

696

697

698

699

700

701

702

703

704

705

706

707

708

709

710

711

712

713

714

715

716

717

718

719

720

721

722

723

724

725
77. Kitzinger K, Koch H, Lücker S, Sedlacek CJ, Herbold C, Schwarz J, et al. Characterization of the first "Candidatus Nitrotoga" isolate reveals metabolic versatility and separate evolution of widespread nitrite-oxidizing bacteria. mBio 2018; 9:e01186-18.

78. Ishii K, Fujitani H, Sekiguchi $\mathrm{Y}$, Tsuneda S. Physiological and genomic characterization of a new "Candidatus Nitrotoga" isolate. Environ Microbiol 2020; 22:2365-82.

79. Starkenburg SR, Chain PSG, Sayavedra-Soto LA, Hauser L, Land ML, Larimer FW, et al. Genome sequence of the chemolithoautotrophic nitrite-oxidizing bacterium Nitrobacter winogradskyi Nb-255. Appl Environ Microbiol 2006; 72:2050-63.

80. Lücker S, Wagner M, Maixner F, Pelletier E, Koch H, Vacherie B, et al. A Nitrospira metagenome illuminates the physiology and evolution of globally important nitrite-oxidizing bacteria. Proc Natl Acad Sci USA 2010; 107:13479-84.

81. Lücker S, Nowka B, Rattei T, Spieck E, Daims H. The genome of Nitrospina gracilis illuminates the metabolism and evolution of the major marine nitrite oxidizer. Front Microbiol 2013; 4:27.

82. Mundinger $\mathrm{AB}$, Lawson $\mathrm{CE}$, Jetten MSM, Koch H, Lücker S. Cultivation and transcriptional analysis of a canonical Nitrospira under stable growth conditions. Front Microbiol 2019; 10:1325.

83. Sancar A. Structure and function of DNA photolyase and cryptochrome blue-light photoreceptors. Chem Rev 2003; 103:2203-38.

84. Zadow A von, Ignatz E, Pokorny R, Essen L-O, Klug G. Rhodobacter sphaeroides CryB is a bacterial cryptochrome with (6-4) photolyase activity. FEBS J 2016; 283:4291-309.

85. Zhang F, Scheerer P, Oberpichler I, Lamparter T, Krauß N. Crystal structure of a prokaryotic (6-4) photolyase with an Fe-S cluster and a 6,7-dimethyl-8-ribityllumazine antenna chromophore. Proc Natl Acad Sci USA 2013; 110:7217-22.

86. Maresca JA, Keffer JL, Hempel PP, Polson SW, Shevchenko O, Bhavsar J, et al. Light modulates the physiology of nonphototrophic Actinobacteria. J Bacteriol 2019; 201: e00740-18.

87. Wink DA, Kasprzak KS, Maragos CM, Elespuru RK, Misra M, Dunams TM, et al. DNA deaminating ability and genotoxicity of nitric oxide and its progenitors. Science 1991; 254:1001-3.

88. Imlay JA. The molecular mechanisms and physiological consequences of oxidative stress: lessons from a model bacterium. Nat Rev Microbiol 2013; 11:443-54.

89. Zhang T, Hansel CM, Voelker BM, Lamborg CH. Extensive dark biological production of reactive oxygen species in brackish and freshwater ponds. Environ Sci Technol 2016; 50:2983-93.

90. Khademian M, Imlay JA. Escherichia coli cytochrome $c$ peroxidase is a respiratory oxidase that enables the use of hydrogen peroxide as a terminal electron acceptor. Proc Natl Acad Sci USA 2017; 114:E6922-31.

91. O'Reilly CM, Sharma S, Gray DK, Hampton SE, Read JS, Rowley RJ, et al. Rapid and highly variable warming of lake surface waters around the globe. Geophys Res Lett 2015; 42:10773-10781.

92. Sterner RW, Keeler B, Polasky S, Poudel R, Rhude K, Rogers M. Ecosystem services of Earth's largest freshwater lakes. Ecosystem Services 2020; 41:101046.

93. Murphy TP. Ammonia and nitrate uptake in the lower Great Lakes. Can J Fish Aq Sci 1980; 37:1365-72.

94. Gardner WS, Lavrentyev PJ, Cavaletto JF, McCarthy MJ, Eadie BJ, Johengen TH, et al. Distribution and dynamics of nitrogen and microbial plankton in southern Lake Michigan during spring transition 1999-2000. J Geophys Res 2004; 109: C03007. 


\section{Figure Legends}

727 Figure 1. Dissolved inorganic nitrogen availability and distribution of nitrifiers across the Great

728 Lakes. (a) Oxidized nitrogen concentrations. Values include NOx concentrations from published

729 studies ( $n=128$; ref. 16,36,38,93,94), US EPA Water Quality Surveys in 2012 and $2013(n=1626$

730 from GLENDA database), and this study ( $\mathrm{n}=20)$ (Table S2). (b) Ammonium concentrations.

731 Values are derived from the literature as in $(a)(n=118)$ and from this study $(n=20)($ Table S3).

732 (c) Distribution of nitrifiers across the Great Lakes. Top panel: map of sampling stations. Stars

733 indicate stations chosen for metagenome analysis. Bottom panel: relative abundance of

734 ammonia-oxidizing (green) and nitrite-oxidizing (pink) families based on 16S rRNA V4-V5

735 amplicon sequencing, sampled in the mid-hypolimnion (except western Erie, sampled $1 \mathrm{~m}$ from

736 bottom). Data is plotted roughly west to east as indicated on the map.

738 Figure 2. Genome properties and cross-lake distribution of ammonia oxidizing organisms,

739 showing both Archaea (top) and Betaproteobacteria (bottom). Rows highlighted in green

740 represent clusters of genomes reconstructed from the Great Lakes; expanded phylogenetic

741 trees are shown in Figures S2 and S5. For catalase, "E" indicates monofunctional catalase katE;

742 "G" indicates bifunctional catalase-peroxidase katG. For carbon fixation, RuBisCO type is shown

743 in parentheses (68); HP/HB, 3-Hydroxypropionate/4-Hydroxybutyrate cycle; CBB, Calvin-

744 Benson-Bassham cycle. Bubble plot shows composition of ammonia oxidizers in hypolimnion

745 samples, using MAGs as probes to recruit metagenomic reads (values sum to $100 \%$ for each

746 lake column). Genes identified in only a subset of genomes are shown as (+).

748 Figure 3. Evidence for proteorhodopsin (PR) in Nitrosospira from the Great Lakes. (a) Gene

749 neighborhood surrounding PR in Nitrosospira MAG MC17_S15_bin_110 and SAG 207399.

750 Genes are colored according to the best BLAST hit taxonomy in the NCBI nr database. (b)

751 Alignment of predicted Nitrosospira PR with reference sequences. Diagnostic features are 
752 highlighted $(61,62)$ : blue boxes, diagnostic residues for PR; pink box, residue indicative of blue

753 or green tuning; green underline, shorter beta-sheet region in PR. Sequence accession

754 numbers: bacteriorhodopsin P02945, actinorhodopsin A0A1D9E0H1, sensory rhodopsin

755 P42196, Dokdonia PR EAQ40507.1, SAR86 blue-tuned PR Q4PP54, SAR86 green-tuned PR

756 Q9F7P4, SAR11 PR A6YQL7.

757

758 Figure 4. Genome properties and cross-lake distribution of nitrite oxidizing taxa Nitrospira (top)

759 and Ca. Nitrotoga (Betaproteobacteria; bottom). Rows highlighted in pink represent clusters of

760 genomes reconstructed from the Great Lakes. Expanded phylogenetic trees are shown in

761 Figures S2 and S6. rTCA, reductive tricarboxylic acid cycle; CBB, Calvin-Benson-Bassham

762 cycle; ONR, octaheme nitrite reductase. Values in parentheses indicate RuBisCO type (68).

763 Bubble plot shows composition of NOB per lake based on metagenomic read mapping. Genes

764 identified in only a subset of genomes are indicated by $(+)$.

765

766 Figure 5. Distinct photolyase proteins in NspiraGL. a) Phylogenetic tree showing families of

767 photolyases. Three families are found in NspiraGL: CPD class I photolyase, FeS-BCP / CRYPro

768 family, and an uncharacterized CPF-related family found in diverse Bacteria. CPD Class I

769 photolyases are also found in other nitrifiers including Ca. Nitrotoga NtogaGL1a, Nitrosospira

770 NspGL1, and Nitrosoarchaeum NarchGL. b) Domain structure of the three photolyase families

771 present in NspiraGL. 


\section{Acknowledgments}

774 Sequencing support for this project was provided by the DOE Joint Genome Institute

775 Community Sequencing Program (CSP \#1565, \#503460). Computational resources were

776 provided by the UChicago Research Computing Center. Funding for this work was provided by

777 Illinois-Indiana Sea Grant (Grant \# NA14OAR170095), UChicago Women's Board, and the

778 National Science Foundation (OCE-1830011 to MLC). We thank Glenn Warren and the science

779 staff in the Great Lakes National Program Office of the US EPA, and the captain and crew of the

780 R/V Lake Guardian, for facilitating sample collection. We thank members of the Coleman and

781 Waldbauer labs for assistance with sample collection and processing, and for discussion and

782 comments on the manuscript.

783

784 Data Availability

785 The metagenome-assembled genomes presented here are available via NCBI BioProject

786 PRJNA636190. 16S rRNA data is available at NCBI BioProject PRJNA591360. Metagenomes

787 sequenced by JGI are available at http://genome.jgi.doe.gov, Project IDs 1045056, 1045059,

788 1045062, 1045065, 1045068, 1045071. Single cell amplified genome is available at

789 img.jgi.doe.gov, IMG Genome ID 3300033241.

790

791 Competing Interests

792 The authors declare no competing interests. 
bioRxiv preprint doi: https://doi.org/10.1101/2021.01.19.427344; this version posted January 20, 2021. The copyright holder for this preprint (which was not certified by peer review) is the author/funder, who has granted bioRxiv a license to display the preprint in perpetuity. It is made available under aCC-BY-NC-ND 4.0 International license.

\section{Figure 1}
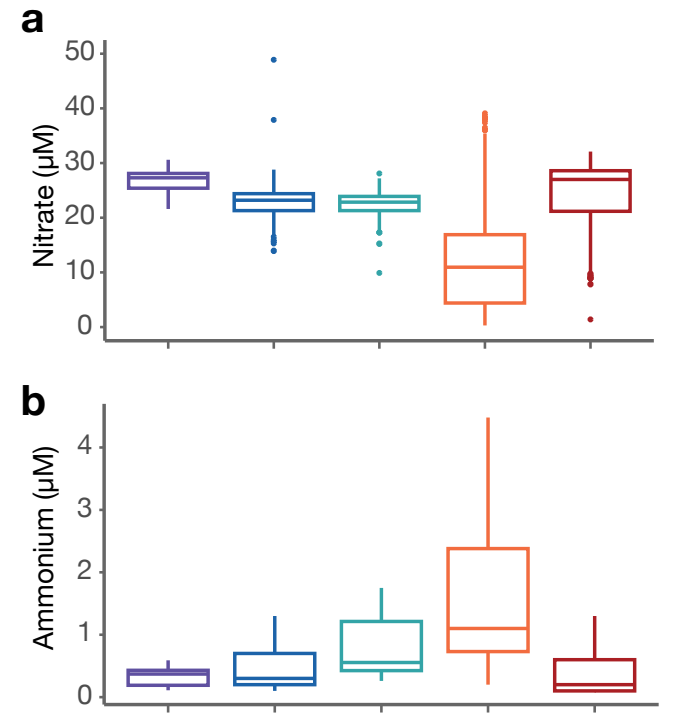

C $\quad-90^{\circ} \mathrm{W}$

$-85^{\circ} \mathrm{W}$

$-80^{\circ} \mathrm{W}$

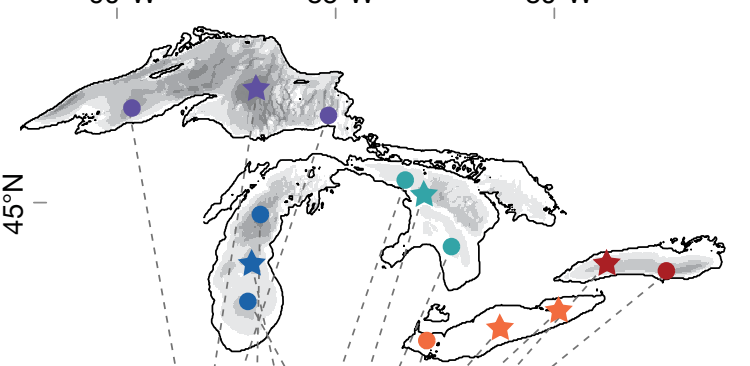

Lake

- Superior

- Michigan

- Huron

- Erie

- Ontario

Nitrifier families

- Nitrosomonadaceae

o Nitrosopumilaceae

o Gallionellaceae

- Nitrospiraceae
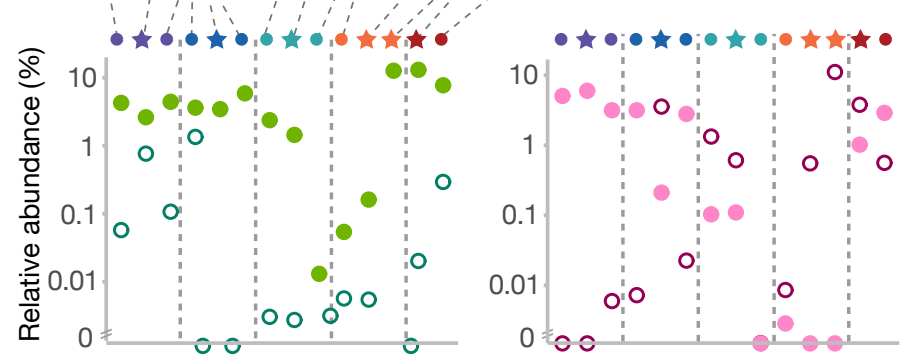
bioRxiv preprint doi: https://doi.org/10.1101/2021.01.19.427344; this version posted January 20, 2021. The copyright holder for this preprint (which was not certified by peer review) is the author/funder, who has granted bioRxiv a license to display the preprint in perpetuity. It is made available under aCC-BY-NC-ND 4.0 International license.

\section{Figure 2}

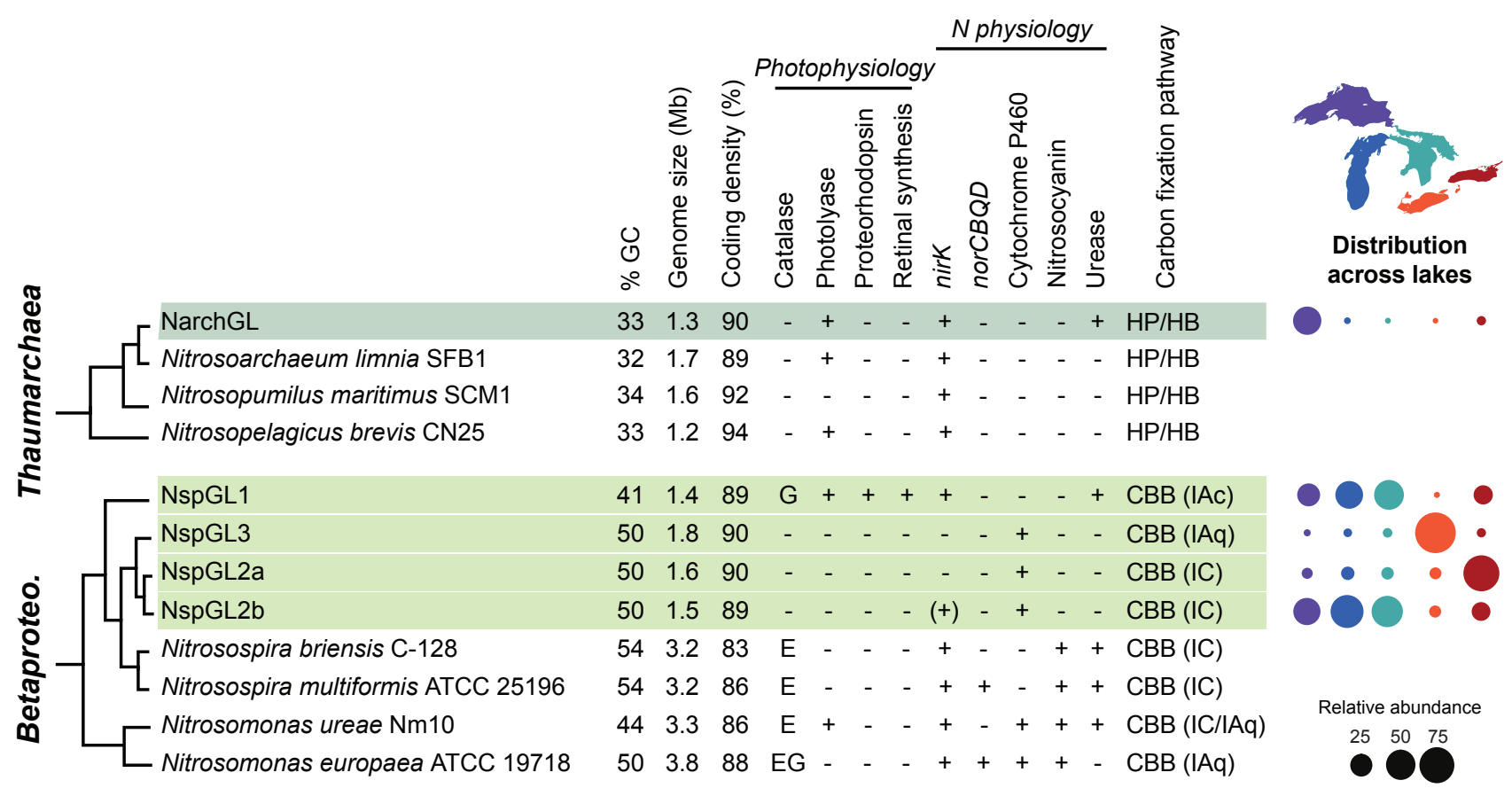


bioRxiv preprint doi: https://doi.org/10.1101/2021.01.19.427344; this version posted January 20, 2021. The copyright holder for this preprint (which was not certified by peer review) is the author/funder, who has granted bioRxiv a license to display the preprint in perpetuity. It is made available under aCC-BY-NC-ND 4.0 International license.

\section{Figure 3}

a

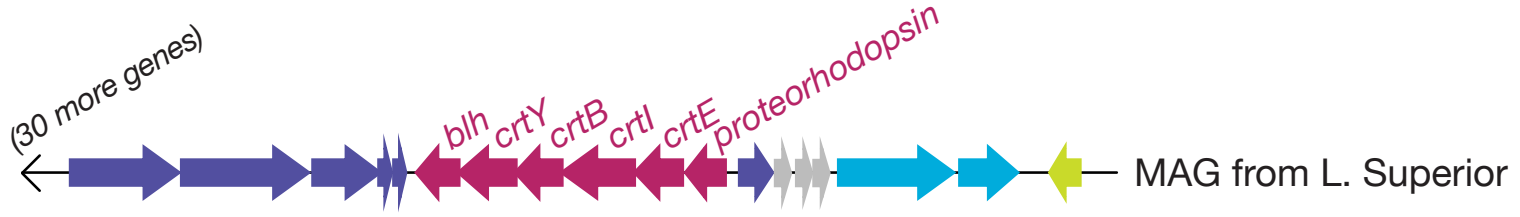

Nitrosomonadaceae isolates/MAGs

Polynucleobacter

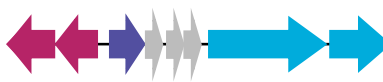

SAG from L. Michigan

Methylophilaceae MAGs

Ca. Nitrotoga sp. LAW

no hits

b

Bacteriorhodopsin

Actinorhodopsin

Sensory rhodopsin

Dokdonia PR

SAR86 PR (blue-tuned)

SAR86 PR (green-tuned)

SAR11 PR

Type 1 Nitrosospira PR
$90 \quad 100 \quad 110 \quad 120 \quad 130 \quad 140$

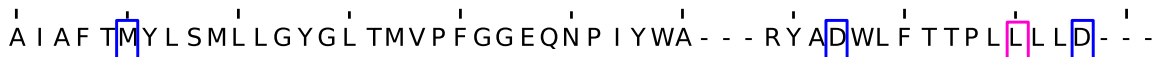
A I AAYHYFRMFDSFNH - - AF AGAEGNPDLYNVGYRYVDWF L TVPLLLVEETVA G I AAVIAYVVMALGVGW- - VPVAE - - R TVFAP - - RY IDWILTTPL| IV - - - Y F I AAVH YWYMRDY - - W - Q QANAE - - SPTFF - - - RYVDWVL TVPLMCVEFFL GVAFWHYLYMRGV - - W - IYAGE - TPTVF - - - RY IDWL I TVPLQI IEFYL G I AF WHYMYMRGV - - W - I ETGD - - SP TVF - - - RY IDWL L TVPLLI ICEFYL G I AF I HYYMYMRDV - - W - VMTGE - SP TVY - - - RY IDWL I TVPLLMLEFYF LVAAVHYFYMRDV - - W - - VATGS - - TP TVY - - - RY IDLL I TVPLLM IEFYL 
bioRxiv preprint doi: https://doi.org/10.1101/2021.01.19.427344; this version posted January 20, 2021. The copyright holder for this preprint (which was not certified by peer review) is the author/funder, who has granted bioRxiv a license to display the preprint in perpetuity. It is made available under aCC-BY-NC-ND 4.0 International license.

\section{Figure 4}

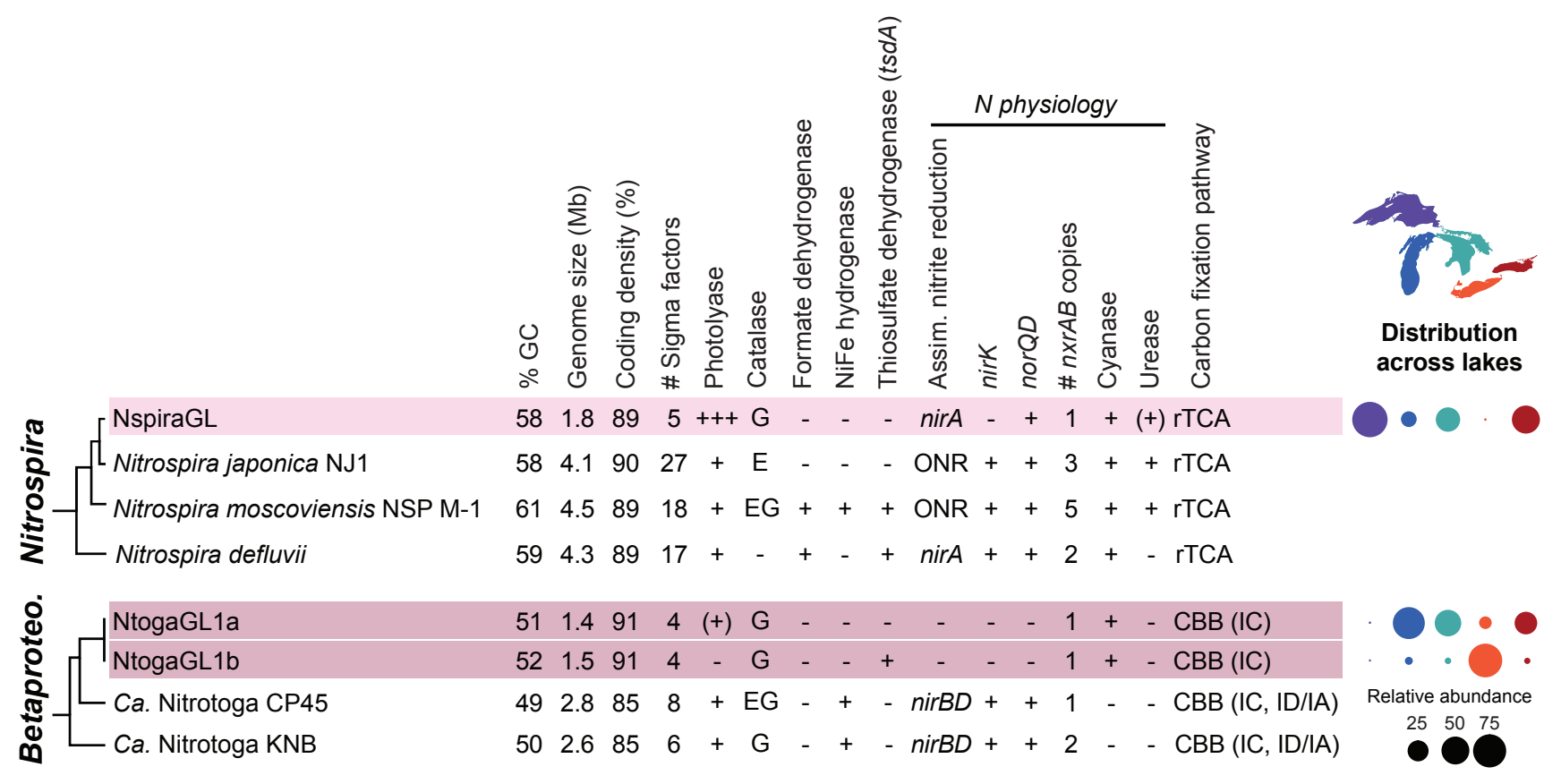


Figube 5 xiv preprint doi: https://doi.org/10.1101/2021.01.19.427344; this version posted January 20, 2021. The copyright holder for this preprint (which was not certified by peer review) is the author/funder, who has granted bioRxiv a license to display the preprint in perpetuity. It is made

a

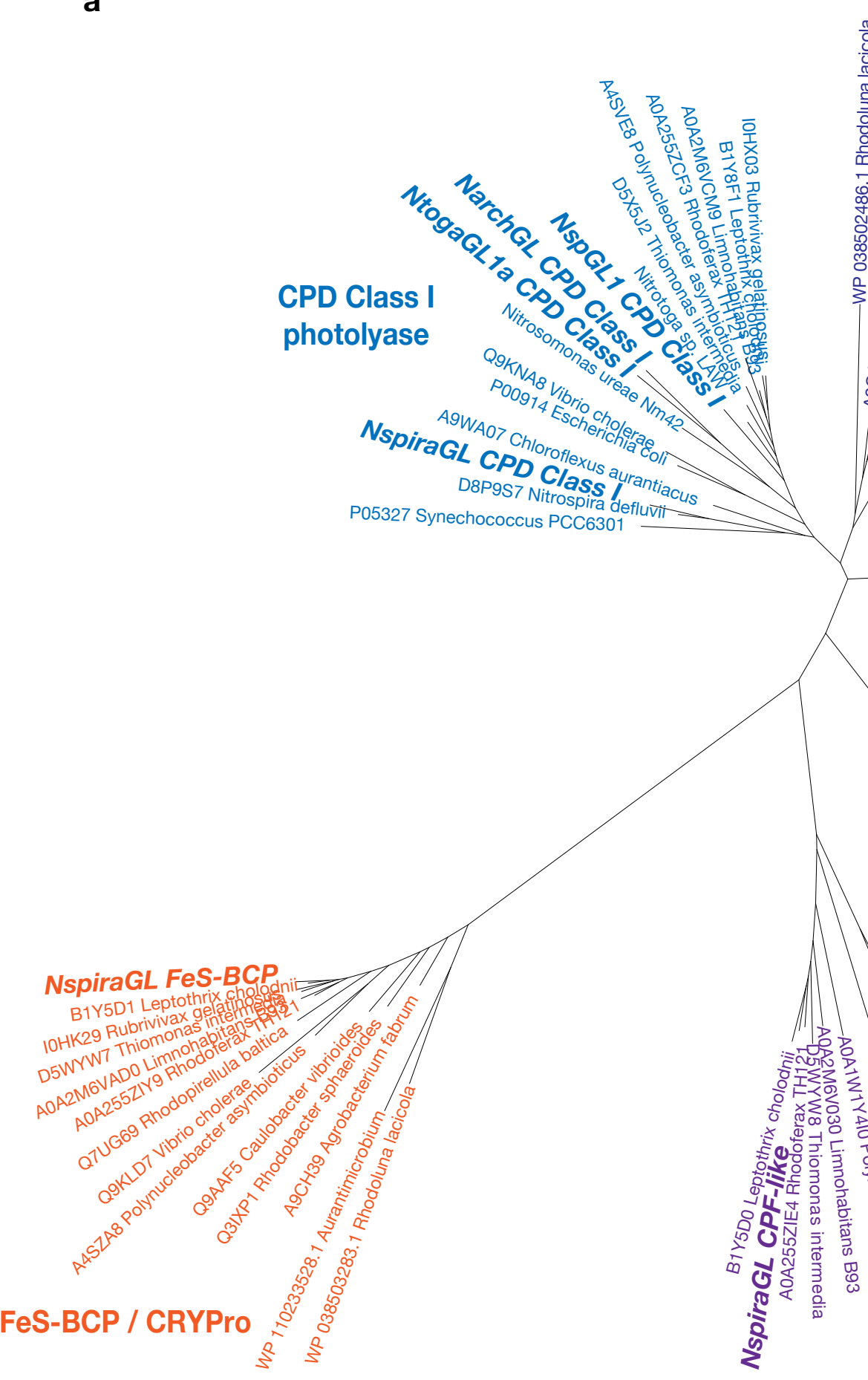
CPD Class III photolyase

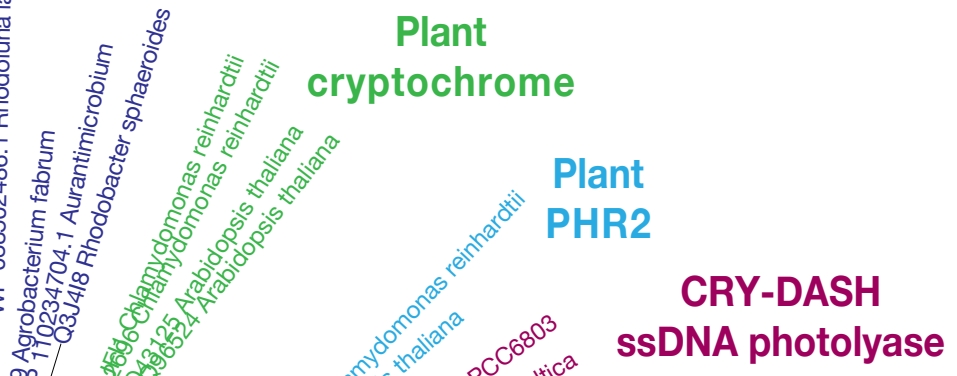

\section{ssDNA photolyase}

6-4) photolyase \& -B7F764 Phaeodactylum tricornutum
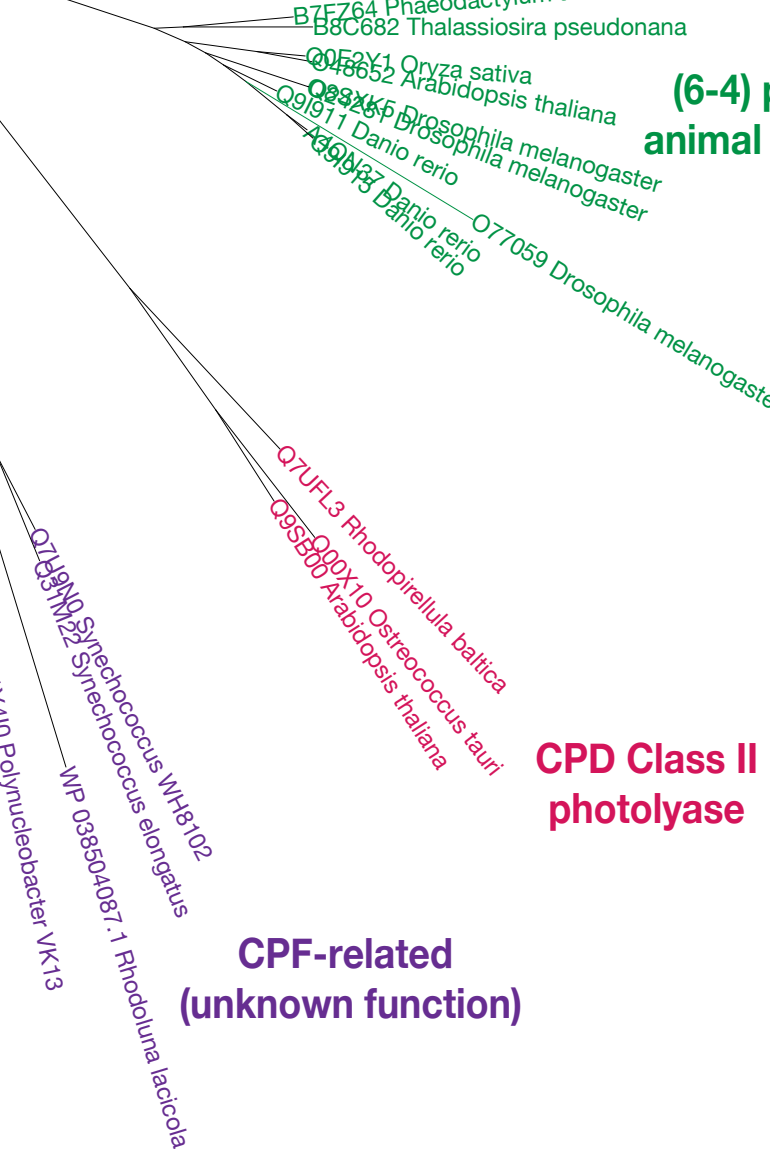

b

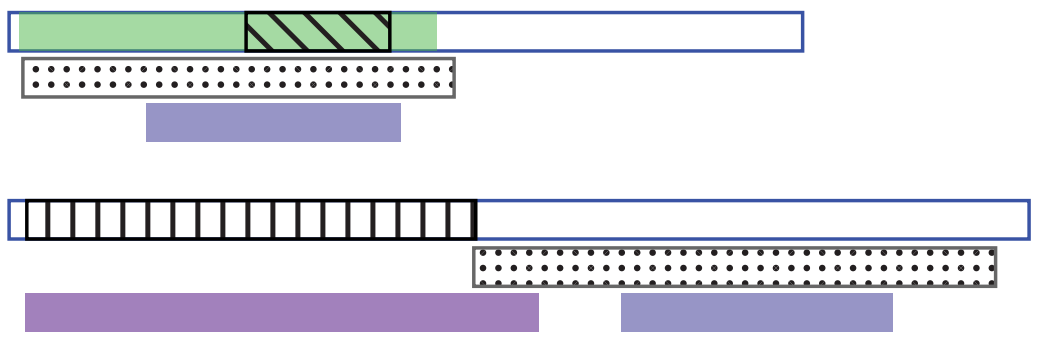

\section{Uncharacterized photolyase-related protein}

FeS-BCP

(6-4) photolyase

Class I CPD photolyase
COG0415

DIPR002081

IIPR014729

$\because::$ SSF48173

SSF52425

PF03441

PF04244

PF00875 


\section{Supplementary Information}

\section{Extended Methods}

\section{Metagenome QC and Assembly}

Raw reads for spring surface samples were quality controlled at the Joint Genome Institute, using bbduk.sh for adapter trimming (ktrim=r, minlen=40, minlenfraction=0.6, mink=11, tbo, tpe, $\mathrm{k}=23$, hdist=1, hdist2 $=1, \mathrm{ftm}=5$ ) and quality filtering ( $\mathrm{maq}=8$, maxns=1, minlen=40, minlenfraction=0.6, $\mathrm{k}=27$, hdist=1, trimq=12, qtrim=rl). Raw reads for summer hypolimnion samples were adapter trimmed, quality filtered, and interleaved using bbduk (parameters: ktrim $=r$, mink=8, hdist=2, $k=21$, forcetrimleft=10, forcetrimright=199, minlen=150) using BBTools suite version 35.74 (https://sourceforge.net/projects/bbmap/). Separate assemblies of quality filtered reads were carried out for each metagenome using metaSPAdes 3.1.11 --meta mode using default $\mathrm{k}$ sizes of $21,33,55$ (1). For mapping, forward and reverse reads were merged using bbmerge in BBtools, using qtrim2=r trimq=10,13,16 and adapter=default. Merged short reads from all 12 metagenomes were mapped onto each assembly using bowtie2 in --sensitive mode (2), and together this information was used to bin assembled contigs. Binning was performed using MetaBAT2 (3), Binsanity (4) and CONCOCT (5) using default parameters. The resulting bins were scored, aggregated, and de-replicated using DAS_Tool (6) followed by manual curation using Anvi'o (7). We assessed genome completion and contamination of manually curated bins using CheckM lineage_wf (8), and all genomes presented here are greater than $70 \%$ complete and have less than $10 \%$ contamination (Table S1). Potential nitrifiers were screened by searching for ammonia monooxygenase, hydroxylamine oxidoreductase and nitrite oxidoreductase within reconstructed genomes using blastp (9). For bins where any of these genes were detected, we identified bacterial single copy core genes (10) or archaeal single copy core genes (11) using HMMER (12), as implemented in Anvi'o. Single copy core genes were queried against proteins predicted from bacterial and archaeal 
genomes in RefSeq (13), and taxonomic identity of these core genes was ascertained based on a least common ancestor approach using a $0.1 \%$ window around the bit score of the best hit using KronaTools (14). Taxonomic assignment was further validated using GTDB-tk (15). Grouping of MAGs into clades and subclades based on ANI was carried out using fastANI (16).

\section{$\underline{\text { Annotation and gene clustering }}$}

Genes from putative nitrifier genomes were annotated using InterProScan 5.30-69.0 (17) and eggnog-mapper against the bactNOG database (18). Gene cluster analysis was carried out using the Anvi'o pangenome pipeline (19), using blastp to determine sequence similarity, ITEP to eliminate weak similarity (20) and MCL to cluster, using a minbit of $0.5, \mathrm{MCL}$ inflation of 2 and minimum gene occurrence of 1 (21). Assignment of KEGG Orthology to gene clusters was carried out using GhostKOALA (22). Sigma factors were tallied by identifying gene clusters annotated with the following PFAMs: PF00309, PF03979, PF00140, PF04542, PF04539, PF04545, PF08281. Prokka (23) was used to generate GenBank file format files from MAGs and SAGs, and genoPlotR (24) was used to generate gene neighborhood maps

\section{Gene tree construction}

The NspGL1 proteorhodopsin sequence was inserted into the MicRhoDE rhodopsin tree using pplacer (25) through the MicRhoDE Galaxy pipeline (26). We then constructed a more targeted phylogenetic tree using aligned reference sequences of Supercluster III from MicRhoDE, filtered to exclude fragments shorter than 220 amino acids. To this alignment, we added NspGL1 sequences using MAFFT (27) along with high similarity sequences from NCBI nr that were not present in MicRhoDE. The tree was inferred using RaxML with model PROTGAMMALG (28). The tree was visualized in ITOL (29) and more distant clusters were collapsed for clarity.

A cyanase phylogenetic tree was created using sequences drawn from querying NtogaGL cyanase against NCBI nr using blastp, as well as sequences from references (30-32). 
Sequences were aligned using MAFFT (27) and the tree was inferred using RaxML with model PROTGAMMALG (28). Tree was visualized in ITOL (29) and branches were colored based on the taxonomy of the parent genome.

Photolyase-related proteins in GL MAGs were identified by searching for the following features: K01669, COG0415, PF03441, PF00875, PF04244, SSF48173, SSF52425. Reference proteins $(n=56)$ spanning the previously defined families of photolyases and cryptochromes (33) were obtained from UniProt, along with aquatic bacterial sequences described by Maresca and colleagues (34). The reference sequences were aligned using MAFFT (27), and sequences from GL MAGs were added using the MAFFT --addfragments option. The tree was estimated using IQ-TREE 2 (35) and visualized using iTOL (29).

\section{Phylogenomic tree construction}

All Nitrospirae, Thaumarchaeota, Gallionellaceae and Nitrosomonadaceae genomes were downloaded from Genbank (36) and included in phylogenetic trees for their respective family. Single copy core genes were extracted as described above and individually aligned at the protein level using muscle (37). Core proteins were then concatenated for each genome. Concatenated alignments were trimmed using Gblocks (38) and analyzed by RAxML 8.2.12 (28) to create a phylogenetic tree using the PROTGAMMALG model and 50 bootstraps. Trees were visualized in iTOL (29).

\section{Proteorhodopsin assembly verification}

We used several approaches to validate the presence of proteorhodopsin in assembled Nitrosospira genomes, to rule out the possibility of chimeric assemblies from different species. We note that proteorhodopsin-containing contigs were independently assembled and binned together with core Nitrosospira contigs from seven different samples (i.e. each sample was 
assembled and binned separately, rather than co-assembled). In five of seven cases, proteorhodopsin and retinal biosynthesis genes were assembled together with core Nitrosospira genes on the same contig. To rule out a systematic reproducible error in assembly and/or binning, we compared these seven MAGs to a single cell amplified Nitrosospira genome (SAG) from Lake Michigan, obtained as part of another project with the JGI. This SAG was processed through JGI's standard decontamination pipeline and manually investigated to ensure lack of contamination. We found no evidence of contaminating core genes, as all core genes had best hits to either Nitrosospira or more generally Nitrosomonadaceae in nr. SAG contigs were matched to homologous contigs from NspGL1 MAGs to determine if any SAG contigs were unique using FastANI (16) with --visualize flag. All contigs from this Nitrosospira SAG were found within an NspGL1 MAG. Bandage (39) was used to manually inspect the assembly graph around the contig that contained the NspGL1 Nitrosospira proteorhodopsin to ensure that the assembled contig did not represent a chimeric contig or inappropriate scaffolding. We verified that a single, unique path exists from the beginning to the end of the NspGL1 contig containing proteorhodopsin (Fig 3, Fig S4). Further, we verified that consistent coverage across this contig existed by mapping short reads from the original sample using bowtie2 (2) and viewing results using Integrated Genomics Viewer (40) A closely related assembly of the same genomic region from Lake Biwa did not show evidence of proteorhodopsin; to confirm this difference between the Biwa and Great Lakes MAGs, we mapped reads from Lake Biwa (41) (BioProject PRJDB6644) onto the assembled contig described above (Fig 3, Fig S4) using bowtie2 (2). This analysis demonstrated that while a large fraction of the NspGL1 contig in question recruited reads from Lake Biwa at high identity (98-99\%), starting upstream of proteorhodopsin and retinal biosynthesis, this contig no longer recruited reads from Lake Biwa.

Manual identification of key nitrification genes

Despite recovery of 15 high completion MAGs in NspGL1/2a/2b/3, many of these MAGs 
lacked key nitrification genes in amo and hao operons. This was largely due to the fact that amo and hao operons were often assembled on small contigs below the minimum size cutoff we imposed for binning contigs. Difficulty in assembling these contigs was likely in part due to the several amo and hao operons with extremely high identity to one another in each genome, a phenomenon which has been observed in other Nitrosospira (42). Manual assembly graph inspection with Bandage (39) supported this hypothesis, as did assessment of abundance of short reads associated with amo operons from NspGL and comparison of abundance of short reads associated with core gene rpoB from NspGL, using ROCker (43). Still, an exemplar MAG from at least one representative of each ecotype (NspGL1/2a/2b/3) was found with both amo and hao operons. Further, manual inspection of unbinned contigs confirmed that amo and hao operons existed on contigs in every sample from which a MAG for a particular ecotype was recovered. That is, for every time that an NspGL1 MAG was recovered from a sample, we were able to determine that an amo and hao operon which could be affiliated with NspGL1 existed, even if it was not correctly binned. Affiliation for these unbinned key nitrification genes was carried out by alignment of $a m o A B$ and hao $A B$ sequences to $a m o A B$ and hao $A B$ sequences correctly binned in NspGL ecotypes. This process was also carried out for two NtogaGL1a MAGs for $n \times r A B$, which were poorly assembled in those two samples.

\section{Data analysis and plots}

All data were analyzed in R version 3.5.3 (44) and plots were generated using ggplot2 (45). 
a

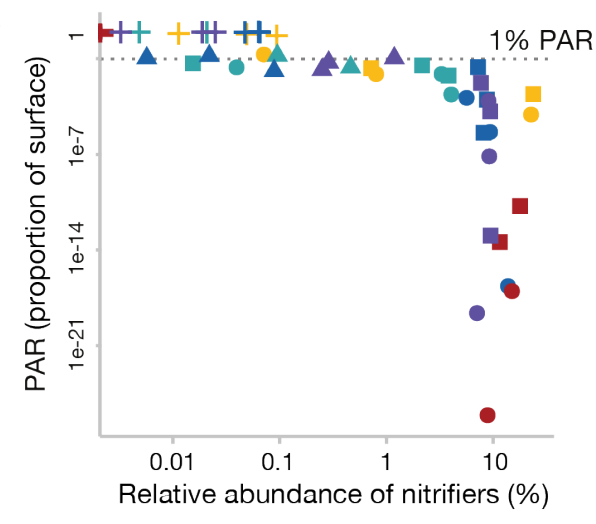

C

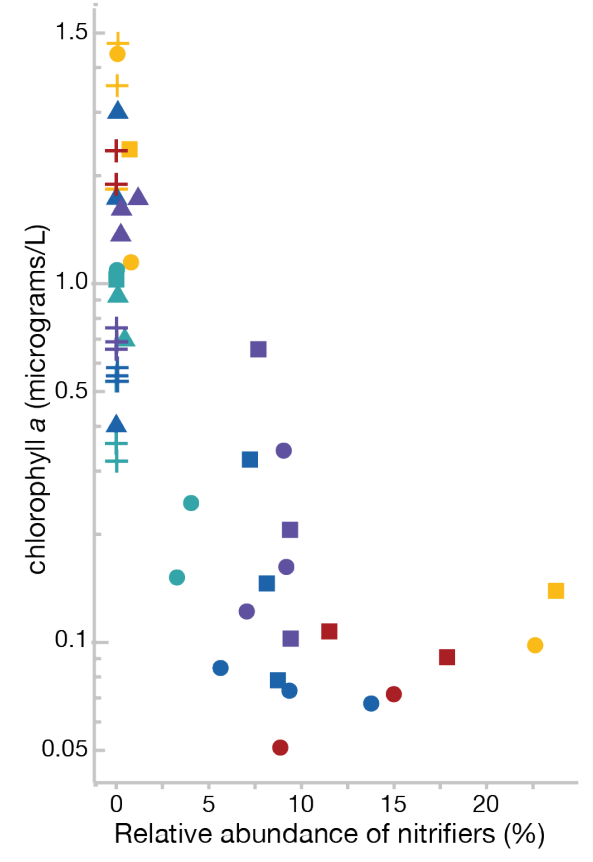

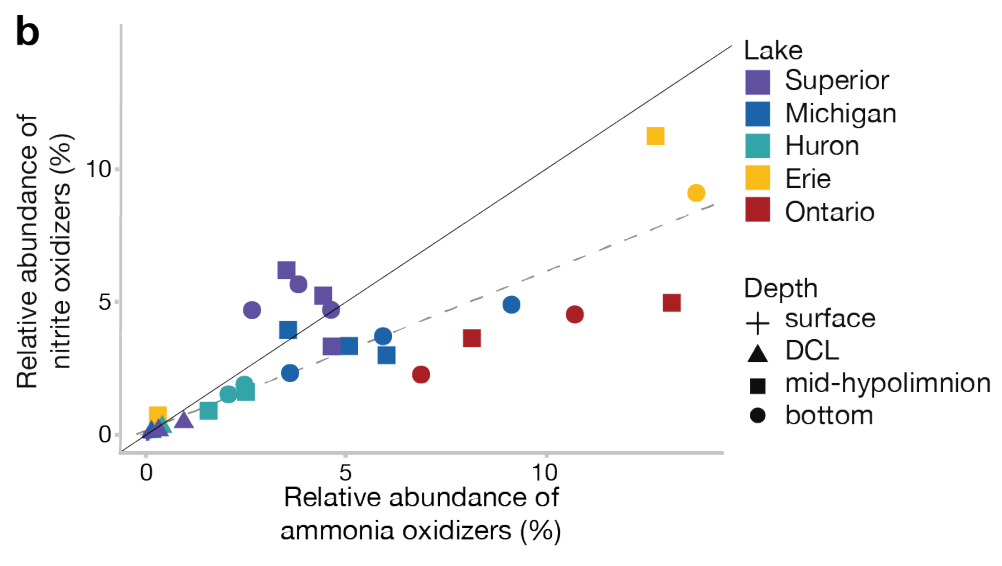

Figure S1. Relationships between environmental factors and relative abundance of nitrifiers in the Great Lakes. Relative abundance based on 16S rRNA V4-V5 region amplicon sequencing from Summer 2012. Nitrifier abundance includes sequences assigned to the familes Nitrosopumilaceae (AOA),

Nitrosomonadaceae (AOB), Nitrospiraceae (NOB), and Gallionellaceae (NOB). (a) Relative abundance of nitrifiers ( $\%$ of total community) compared to photosynthetically active radiation (PAR). (b)

Correlation between the relative abundances of nitrite oxidizers and ammonia oxidizers in each sample. A 1:1 line (solid) and linear regression fit (dashed) are shown for reference. (c) Relative abundance of nitrifiers (\% of total community) compared to chlorophyll $a$ concentration. PAR and chlorophyll data from the EPA Great Lakes Environmental Database (https://cdx.epa.gov/). 
bioRxiv preprint doi: https://doi.org/10.1101/2021.01.19.427344; this version posted January 20, 2021. The copyright holder for this preprint (which was not certified by peer review) is the author/funder, who has granted bioRxiv a license to display the preprint in perpetuity. It is made available under aCC-BY-NC-ND 4.0 International license.

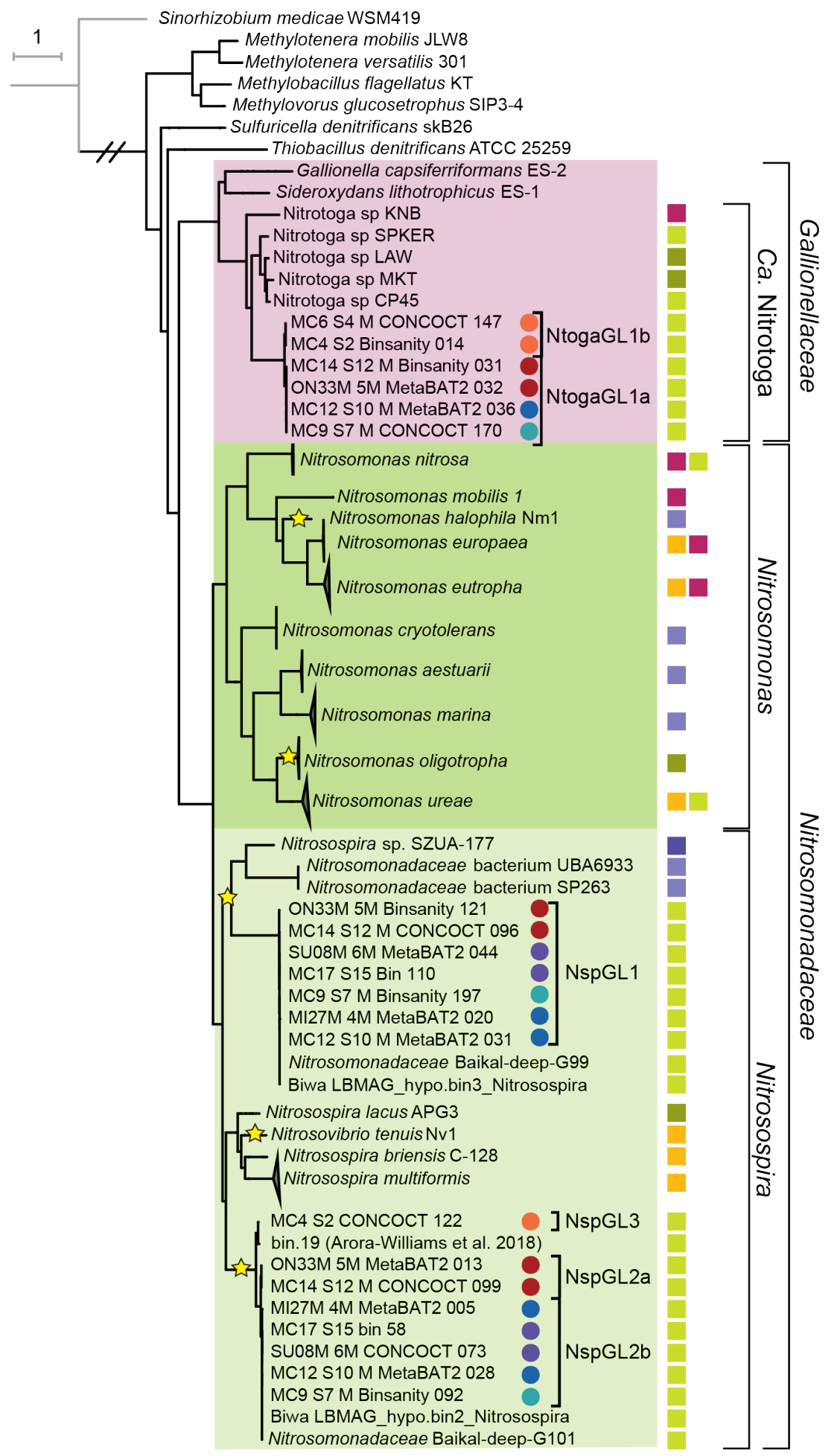

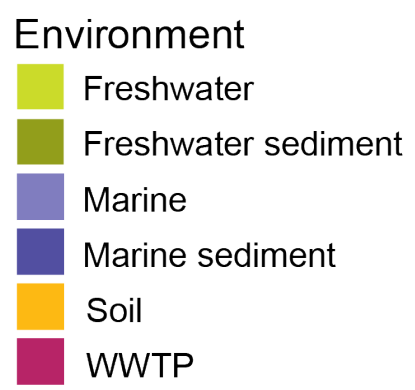
Lake
Superior
Michigan
Huron
Erie
Ontario

Tree scale: $0.1 \mapsto$

Figure S2. Phylogenomic tree of the Nitrosomonadales order of Betaproteobacteria, focusing on the Nitrosomonadaceae and Gallionellaceae families. Tree was constructed using 139 concatenated singlecopy core genes (10). Colored squares indicate the environment of origin; colored circles denote the lake of origin for genomes from the Laurentian Great Lakes; yellow stars indicate clades containing strains that lack nitrosocyanin. 
bioRxiv preprint doi: https://doi.org/10.1101/2021.01.19.427344; this version posted January 20, 2021. The copyright holder for this preprint (which was not certified by peer review) is the author/funder, who has granted bioRxiv a license to display the preprint in perpetuity. It is made available under aCC-BY-NC-ND 4.0 International license.

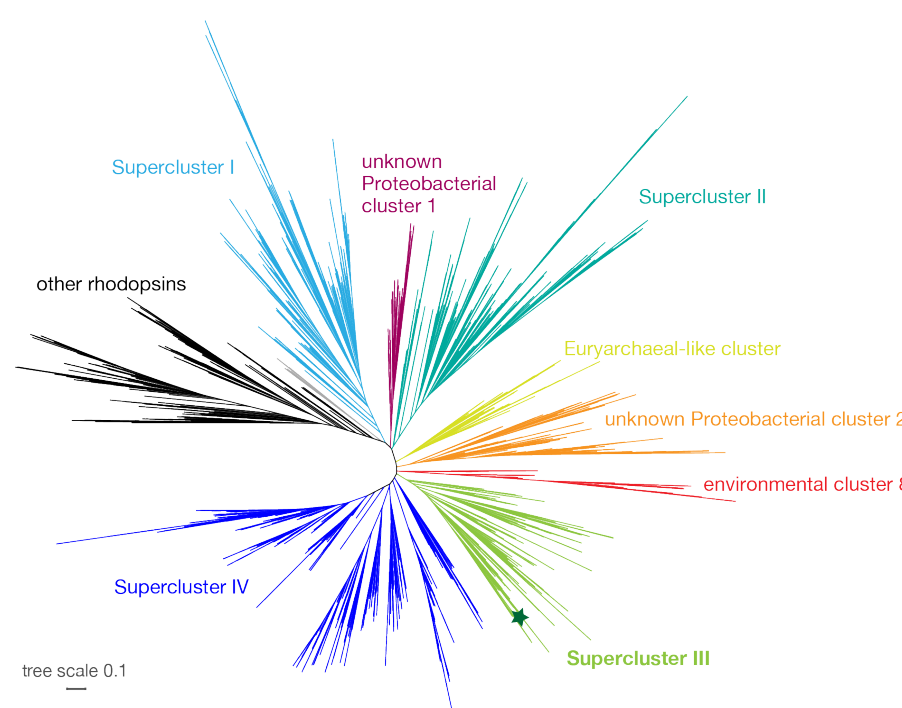

Figure S3. Proteorhodopsin phylogeny. Top: Phylogenetic placement of Nitrosospira PR. Rhodopsin sequences and classifications from MicRhoDE database (26); star shows NspGL1 PR. Bottom: Close relatives of Nitrosospira PR within Supercluster III. Neighboring clusters have been collapsed for clarity.

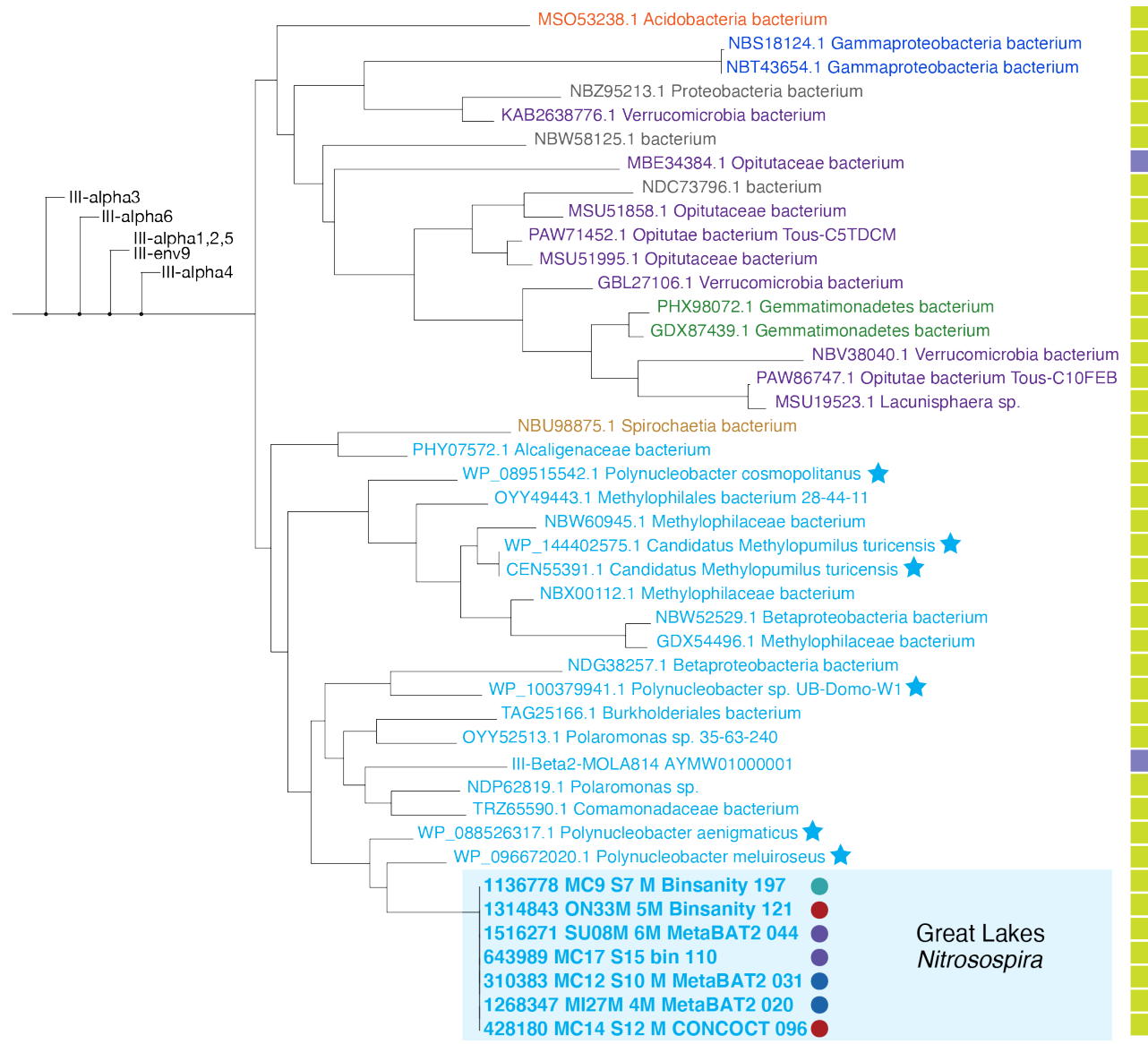

$\begin{array}{cll}\text { Environment } & \text { Lake } & \text { Taxonomy } \\ \text { marine } & \text { Superior } & \text { Betaproteobacteria } \\ \text { freshwater } & \text { Michigan } & \text { Verrucomicrobia } \\ & \text { Huron } & \text { Gammaproteobacteria } \\ & \text { Eemmatimonadetes } \\ \star \text { isolate } & \text { Erie } & \text { Acidobacteria } \\ & \text { Ontario } & \text { Spirochaetes }\end{array}$

Tree scale: $0.1 \longmapsto$ 


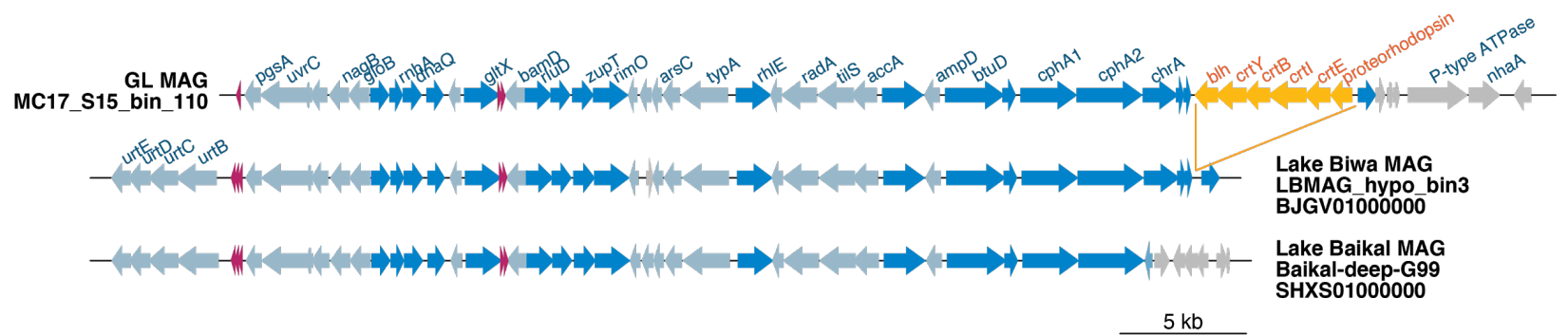

Figure S4. Shared synteny surrounding the proteorhodopsin module in Nitrosospira draft genomes from deep lakes. Light blue, shared genes on reverse strand; dark blue, shared genes on forward strand; pink, tRNA genes; orange, PR module in NspGL1 MAG; gray, genes unique to one MAG. 
bioRxiv preprint doi: https://doi.org/10.1101/2021.01.19.427344; this version posted January 20, 2021. The copyright holder for this preprint (which was not certified by peer review) is the author/funder, who has granted bioRxiv a license to display the preprint in perpetuity. It is made available under aCC-BY-NC-ND 4.0 International license.

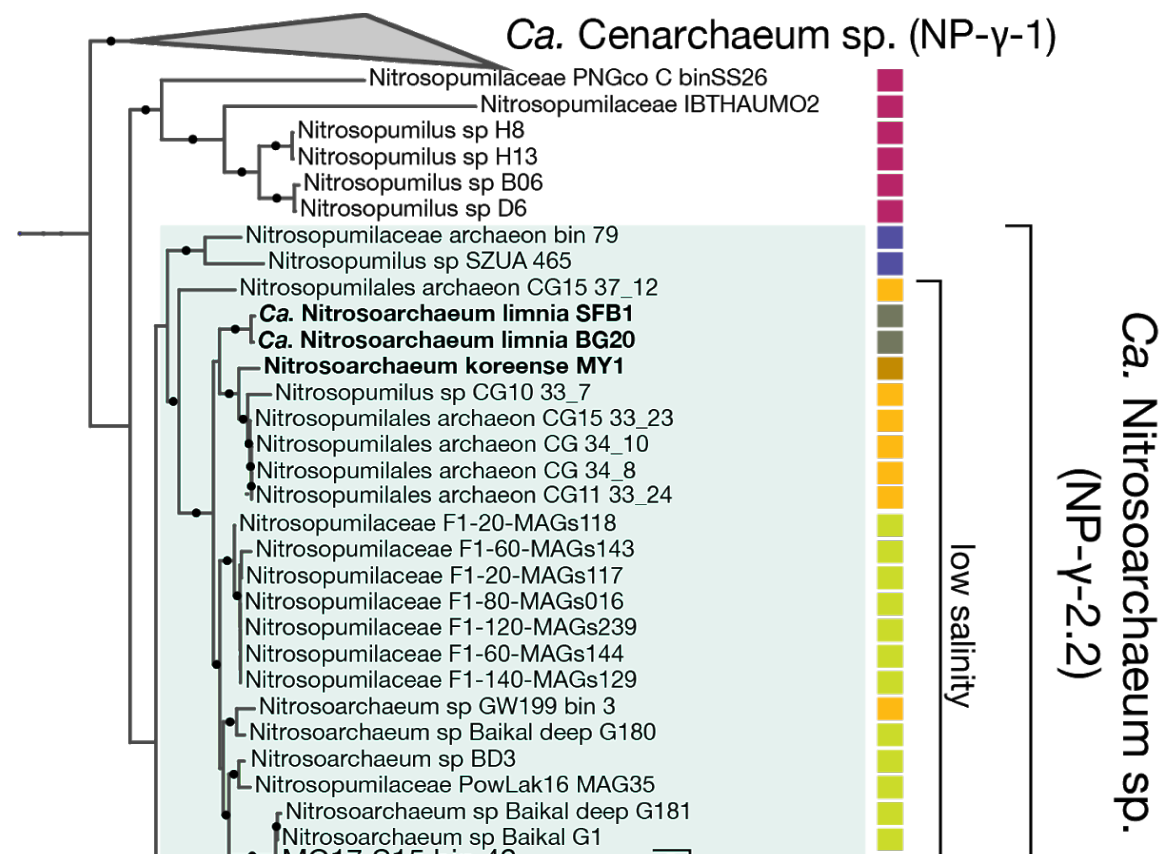

\section{Environment}

Ca. Nitrosopumilus sp SW

- Nitrosopumilus sp GoM MAG6

- Nitrosopumilus sp GoM MAG5

- Nitrosopumilus sp GoM MAG3

Nitrosopumilus sp 33_1

9 Nitrosopumilus sp GoM MAG4

- Thaumarchaeota archaeon casp thauma3

-Thaumarchaeota archaeon SCGC_AAA282_K18

-Thaumarchaeota archaeon NP142

- Nitrosopumilus sp SZUA 238

- Nitrosopumilus sp LS_AOA

Ca. Nitrosopumilus sp NM25

Ca. Nitrosopumilus Sp NM25

Ca. Nitrosopumilus sp DDS1

Ca. Nitrosopumilus salaria BD31

Nitrosopumilus salaria SZUA 335

Nitrosopumilales archaeon CG 34_16

-Nitrosopumilus sp das_tool_concoct_135

Ca. Nitrosopumilus sediminis AR2 Nitrosopumilus sp UBA526 Nitrosopumilus sp UBA527

Thaumarchaeota archaeon Guaymas 69

- uncultured marine group I AG_319_N20

Nitrosopumilus sp BACL13 MAG-121220-bin23

- Nitrosopumilus sp UBA241

Nitrosopumilus sp BACL13 MAG-120910-bin56

-uncultured marine group I AG_319_O22

Ca. Nitrosomarinus catalina SPOT01

Nitrosopumilus sp Nsub

- Nitrosomarinus sp GoM MAG2

- Nitrosopumilus sp MED740

INitrosopumilus sp MED_G94

Thaumarchaeota archaeon Baikal G2

Nitrosopumilus sp Baikal deep G182

- Thaumarchaeota archaeon casp thauma1

Nitrosopumilaceae F1-20-MAGs116

Nitrosopumilaceae F1-140-MAGs130

Nitrosopumilaceae F1-120-MAGs240

Nitrosopumilaceae F1-80-MAGs017

Nitrosopumilaceae F1-60-MAGs142

\section{freshwater}

brackish

brackish sediment

marine

marine sediment

fish tank

groundwater

soil

sponge symbiont

\section{Great Lakes}

- Superior

- Michigan

- Huron

- Erie

- Ontario 
Figure S5. Phylogenomic tree of Nitrosopumilaceae and Cenarchaeum. Tree was constructed using concatenated single-copy core genes as defined in (11). This tree represents a zoomed in view of Nitrosopumilaceae and Cenarchaeum from larger tree of all Thaumarchaeota and Aigarchaeota. Colored boxes correspond to the environment of origin; genomes from the Laurentian Great Lakes are indicated by colored circles. Names in bold indicate cultured isolates or enrichments.

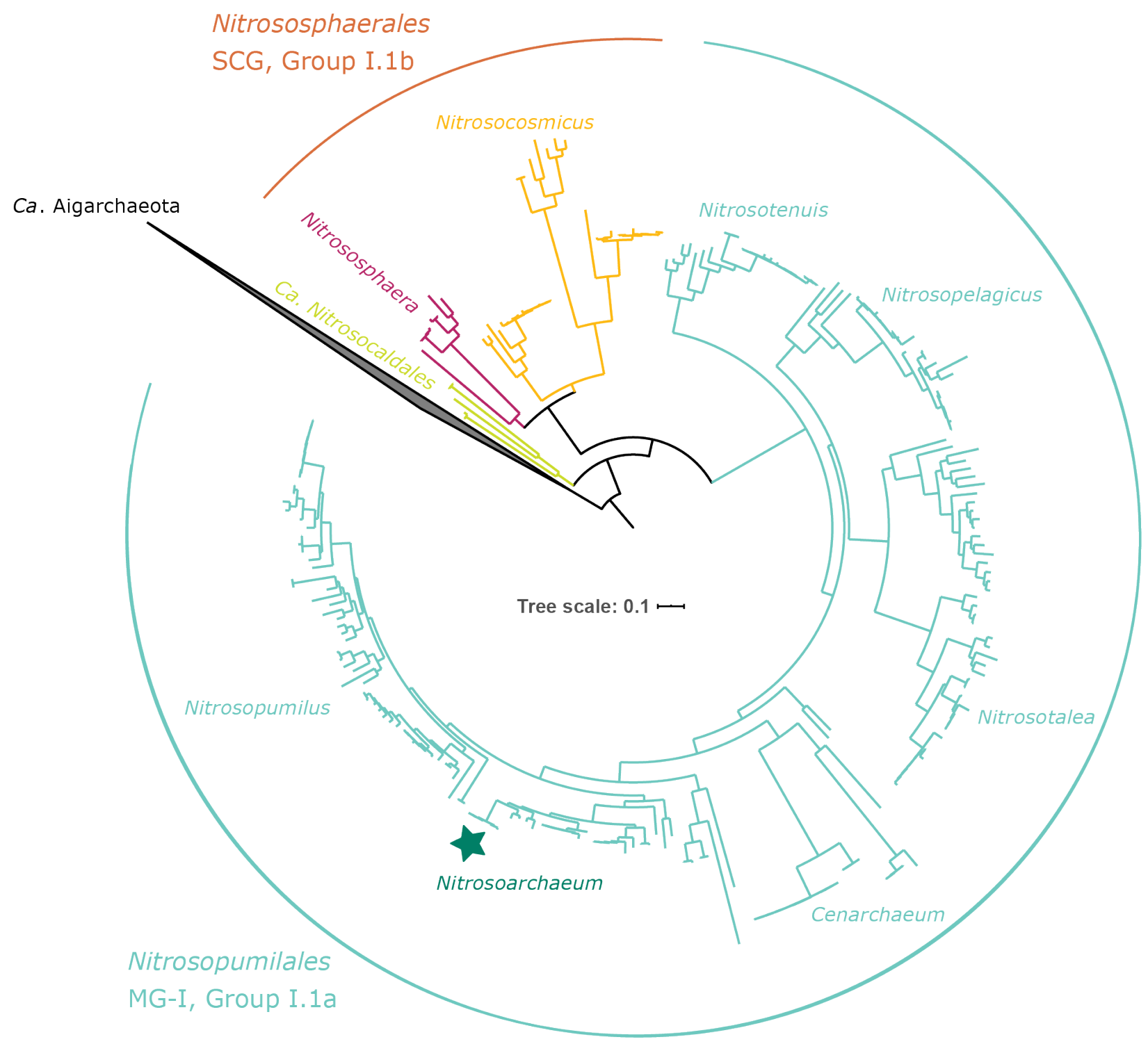

Figure S6. Phylogenomic tree of Thaumarchaeota and Aigarchaeota. Tree was constructed using concatenated single-copy core genes from (11), and all available genomes in Genbank as of February 6 2020. Colors denote clades described in (46). Star indicates placement of NarchGL. 
bioRxiv preprint doi: https://doi.org/10.1101/2021.01.19.427344 this version posted January 20, 2021. The copyright holder for this preprint (which was not certified by peer review) is the author/funder, who has granted bioRxiv a license to display the preprint in perpetuity. It is made available under aCC-BY-NC-ND 4.0 International license.

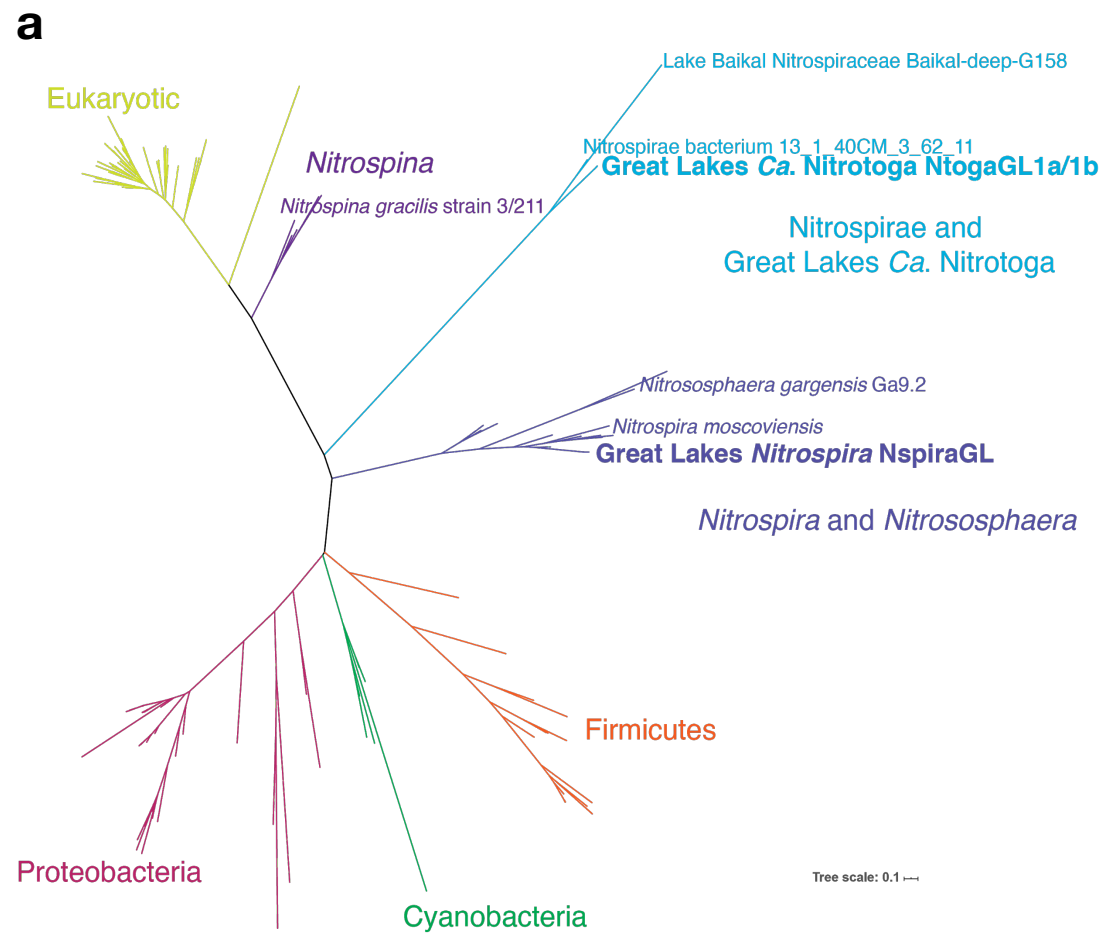

b

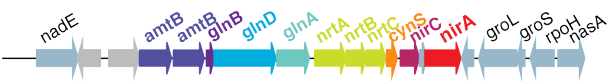

NspiraGL

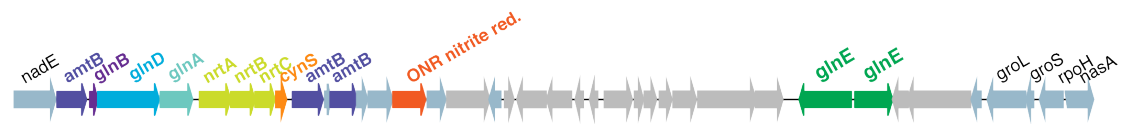

Nitrospira japonica $\mathrm{NJ} 1$

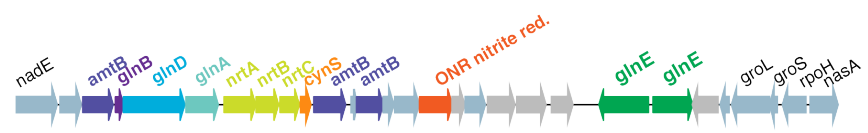

Nitrospira moscoviensis NSP M-1

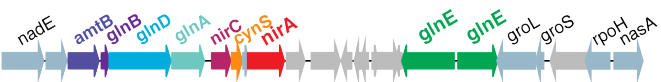

Nitrospira defluvii

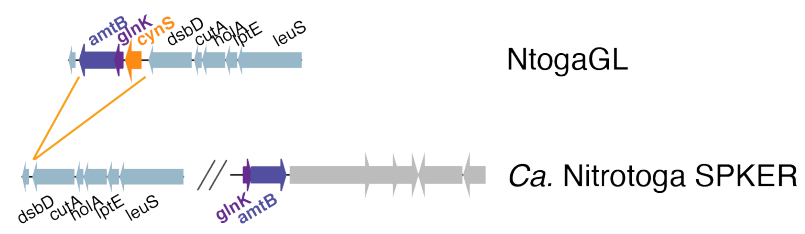

Figure S7. Cyanase diversity and distribution among nitrite oxidizing bacteria. a) Phylogenetic tree showing distinct clades of cyanase, highlighting Great Lakes Nitrospira and Ca. Nitrotoga. b) Gene synteny surrounding the cyanase gene in NspiraGL and reference Nitrospira, and a cyanase insertion in NtogaGL compared to reference $C a$. Nitrotoga. 


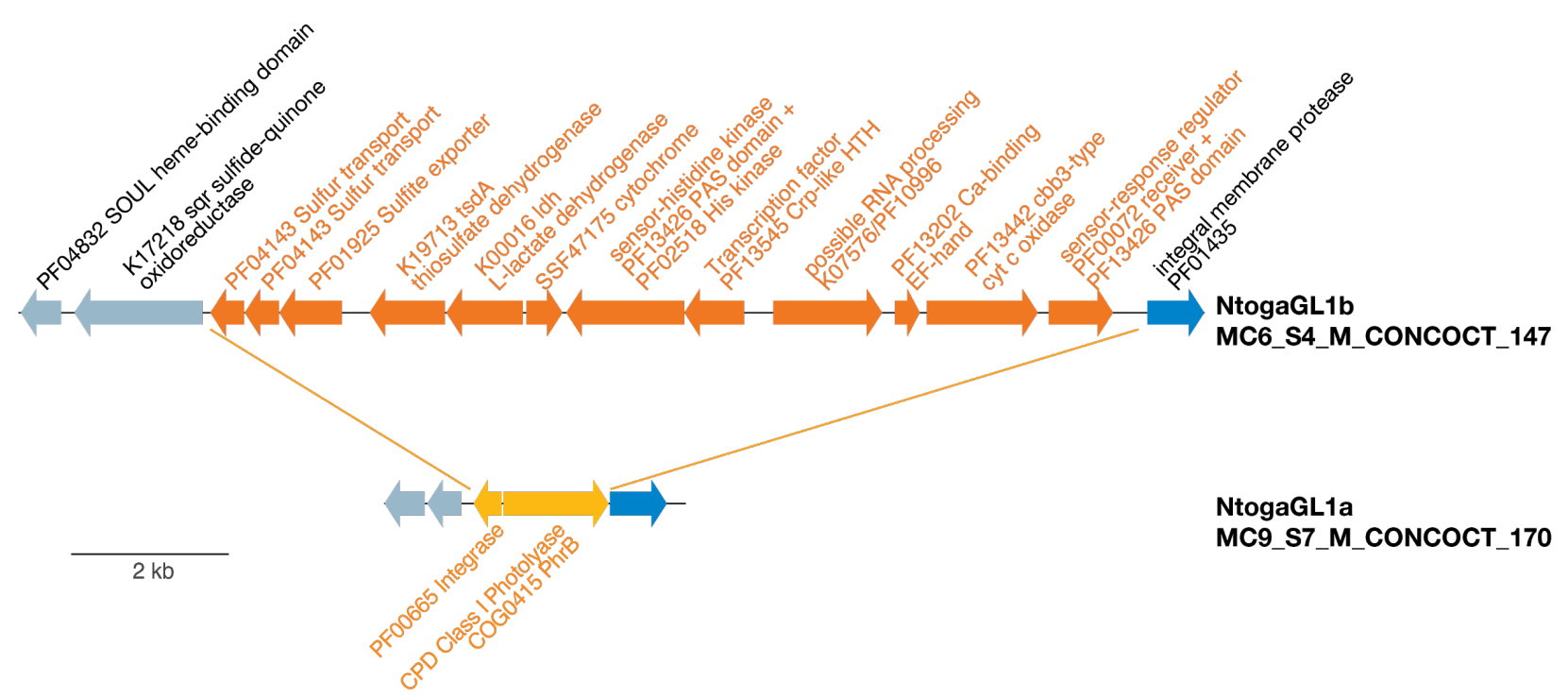

Figure S8. Gene content distinguishing NtogaGL1a and NtogaGL1b. Genes colored in blue are shared between both genomes; orange colored genes are unique to either genome. 
bioRxiv preprint doi: https://doi.org/10.1101/2021.01.19.427344; this version posted January 20, 2021. The copyright holder for this preprint (which was not certified by peer review) is the author/funder, who has granted bioRxiv a license to display the preprint in perpetuity. It is made available under aCC-BY-NC-ND 4.0 International license.

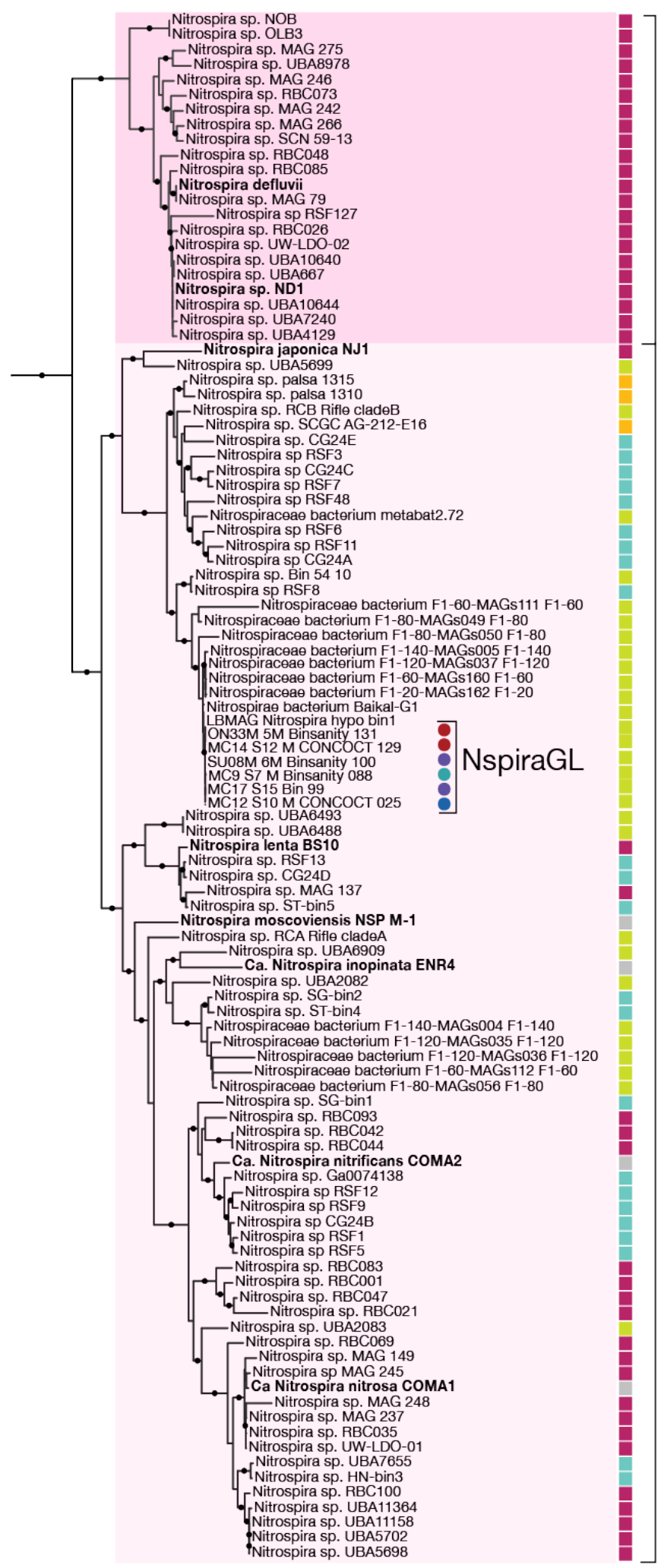

\section{Lineage I}

\section{Lineage II}

\section{Environment}

freshwater

soil

WWTP

drinking water systems

other engineered systems

\section{Great Lakes \\ Superior \\ Michigan \\ Huron \\ Erie}

Ontario

Figure S9. Phylogenomic tree of Lineage I and II Nitrospira. Tree was constructed using concatenated single-copy core genes described in (10). Colored boxes correspond to the environment of origin; genomes from the Laurentian Great Lakes are indicated by circles color coded by lake of origin. 


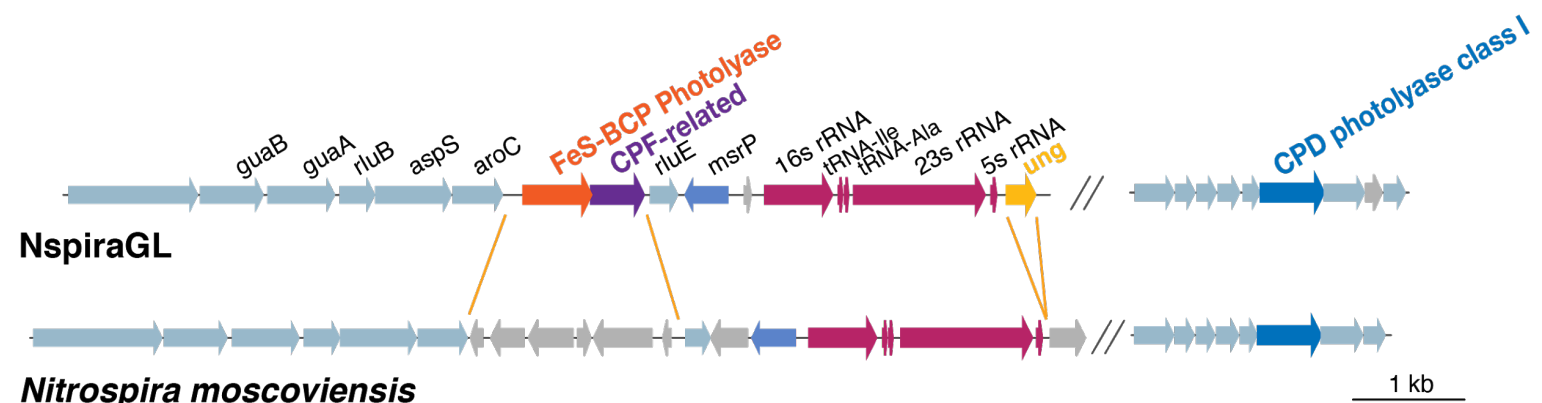

Nitrospira moscoviensis

Figure S10. Gene neighborhood surrounding photolyase genes in NspiraGL, compared to reference $N$. moscoviensis. Genes shared between the two genomes are colored light blue (protein coding) or magenta (rRNA, tRNA); non-shared genes are gray; photolyase genes are colored to match the tree in Figure 5. 


\section{References}

1. Nurk S, Meleshko D, Korobeynikov A, Pevzner PA. metaSPAdes: a new versatile metagenomic assembler. Genome Res 2017; 27:824-34.

2. Langmead B, Salzberg SL. Fast gapped-read alignment with Bowtie 2. Nat Methods 2012; 9:357-9.

3. Kang DD, Froula J, Egan R, Wang Z. MetaBAT, an efficient tool for accurately reconstructing single genomes from complex microbial communities. PeerJ 2015; 3:e1165.

4. Graham ED, Heidelberg JF, Tully BJ. BinSanity: unsupervised clustering of environmental microbial assemblies using coverage and affinity propagation. PeerJ 2017; 5:e3035.

5. Alneberg J, Bjarnason BS, de Bruijn I, Schirmer M, Quick J, ljaz UZ, et al. Binning metagenomic contigs by coverage and composition. Nat Methods 2014; 11:1144-6.

6. Sieber CMK, Probst AJ, Sharrar A, Thomas BC, Hess M, Tringe SG, et al. Recovery of genomes from metagenomes via a dereplication, aggregation and scoring strategy. Nat Microbiol 2018; 3:836-43.

7. Eren AM, Esen ÖC, Quince C, Vineis JH, Morrison HG, Sogin ML, et al. Anvi'o: an advanced analysis and visualization platform for 'omics data. PeerJ 2015; 3:e1319.

8. Parks DH, Imelfort M, Skennerton CT, Hugenholtz P, Tyson GW. CheckM: assessing the quality of microbial genomes recovered from isolates, single cells, and metagenomes. Genome Res 2015; 25:1043-55.

9. Camacho C, Coulouris G, Avagyan V, Ma N, Papadopoulos J, Bealer K, et al. BLAST+: architecture and applications. BMC Bioinform 2009; 10:421.

10. Campbell BJ, Yu L, Heidelberg JF, Kirchman DL. Activity of abundant and rare bacteria in a coastal ocean. Proc Natl Acad Sci USA 2011; 108:12776-81.

11. Rinke C, Schwientek P, Sczyrba A, Ivanova NN, Anderson IJ, Cheng J-F, et al. Insights into the phylogeny and coding potential of microbial dark matter. Nature 2013; 499:431-7.

12. Mistry J, Finn RD, Eddy SR, Bateman A, Punta M. Challenges in homology search: HMMER3 and convergent evolution of coiled-coil regions. Nucleic Acids Res 2013; 41:e121-e121.

13. O'Leary NA, Wright MW, Brister JR, Ciufo S, Haddad D, McVeigh R, et al. Reference sequence (RefSeq) database at $\mathrm{NCBI}$ : current status, taxonomic expansion, and functional annotation. Nucleic Acids Res 2016; 44:D733-45.

14. Ondov BD, Bergman NH, Phillippy AM. Interactive metagenomic visualization in a Web browser. BMC Bioinform 2011; 12:385.

15. Chaumeil P-A, Mussig AJ, Hugenholtz P, Parks DH. GTDB-Tk: a toolkit to classify genomes with the Genome Taxonomy Database. Bioinformatics 2020; 36:1925-1927.

16. Jain C, Rodriguez-R LM, Phillippy AM, Konstantinidis KT, Aluru S. High throughput ANI analysis of $90 \mathrm{~K}$ prokaryotic genomes reveals clear species boundaries. Nat Commun 2018; 9:1-8.

17. Jones P, Binns D, Chang H-Y, Fraser M, Li W, McAnulla C, et al. InterProScan 5: genomescale protein function classification. Bioinformatics 2014; 30:1236-40.

18. Huerta-Cepas J, Forslund K, Coelho LP, Szklarczyk D, Jensen LJ, von Mering C, et al. Fast genome-wide functional annotation through orthology assignment by eggNOGMapper. Mol Biol Evol 2017; 34:2115-22.

19. Delmont TO, Eren AM. Linking pangenomes and metagenomes: the Prochlorococcus metapangenome. PeerJ 2018; 6:e4320.

20. Benedict MN, Henriksen JR, Metcalf WW, Whitaker RJ, Price ND. ITEP: An integrated toolkit for exploration of microbial pan-genomes. BMC Genomics 2014; $15: 8$.

21. van Dongen $\mathrm{S}$, Abreu-Goodger $\mathrm{C}$. Using MCL to extract clusters from networks. Methods Mol Biol 2012; 804:281-95.

22. Kanehisa M, Sato Y, Morishima K. BlastKOALA and GhostKOALA: KEGG tools for 
functional characterization of genome and metagenome sequences. J Mol Biol 2016; 428:726-31.

23. Seemann T. Prokka: rapid prokaryotic genome annotation. Bioinformatics $2014 ; 30: 2068-$ 9.

24. Guy L, Roat Kultima J, Andersson SGE. genoPlotR: comparative gene and genome visualization in R. Bioinformatics 2010; 26:2334-5.

25. Matsen FA, Kodner RB, Armbrust EV. pplacer: linear time maximum-likelihood and Bayesian phylogenetic placement of sequences onto a fixed reference tree. BMC Bioinform 2010; 11:538.

26. Boeuf D, Audic S, Brillet-Guéguen L, Caron C, Jeanthon C. MicRhoDE: a curated database for the analysis of microbial rhodopsin diversity and evolution. Database (Oxford) 2015; bav080.

27. Katoh K, Misawa K, Kuma K, Miyata T. MAFFT: a novel method for rapid multiple sequence alignment based on fast Fourier transform. Nucleic Acids Res 2002; 30:3059_ 66.

28. Stamatakis A. RAxML version 8: a tool for phylogenetic analysis and post-analysis of large phylogenies. Bioinformatics 2014; 30:1312-3.

29. Letunic I, Bork P. Interactive tree of life (iTOL) v3: an online tool for the display and annotation of phylogenetic and other trees. Nucleic Acids Res 2016; 44:W242-5.

30. Pachiadaki MG, Sintes E, Bergauer K, Brown JM, Record NR, Swan BK, et al. Major role of nitrite-oxidizing bacteria in dark ocean carbon fixation. Science 2017; 358:1046-51.

31. Spang A, Poehlein A, Offre P, Zumbrägel S, Haider S, Rychlik N, et al. The genome of the ammonia-oxidizing Candidatus Nitrososphaera gargensis: insights into metabolic versatility and environmental adaptations. Environ Microbiol 2012; 14:3122-45.

32. Palatinszky M, Herbold C, Jehmlich N, Pogoda M, Han P, von Bergen M, et al. Cyanate as an energy source for nitrifiers. Nature 2015;524:105-8.

33. Vechtomova YuL, Telegina TA, Kritsky MS. Evolution of proteins of the DNA photolyase/cryptochrome family. Biochemistry Moscow 2020; 85:131-53.

34. Maresca JA, Keffer JL, Hempel PP, Polson SW, Shevchenko O, Bhavsar J, et al. Light modulates the physiology of nonphototrophic Actinobacteria. J Bacteriol 2019; 201: e00740-18.

35. Minh BQ, Schmidt HA, Chernomor O, Schrempf D, Woodhams MD, von Haeseler A, et al. IQ-TREE 2: new models and efficient methods for phylogenetic inference in the genomic era. Mol Biol Evol 2020; 37:1530-4.

36. Benson DA, Karsch-Mizrachi I, Lipman DJ, Ostell J, Wheeler DL. GenBank. Nucleic Acids Res 2005; 33:D34-8.

37. Edgar RC. MUSCLE: multiple sequence alignment with high accuracy and high throughput. Nucleic Acids Res 2004; 32:1792-7.

38. Castresana J. Selection of conserved blocks from multiple alignments for their use in phylogenetic analysis. Mol Biol Evol 2000; 17:540-52.

39. Wick RR, Schultz MB, Zobel J, Holt KE. Bandage: interactive visualization of de novo genome assemblies. Bioinformatics 2015; 31:3350-2.

40. Thorvaldsdóttir H, Robinson JT, Mesirov JP. Integrative Genomics Viewer (IGV): highperformance genomics data visualization and exploration. Brief Bioinform 2013; 14:17892.

41. Okazaki Y, Nishimura Y, Yoshida T, Ogata H, Nakano S-I. Genome-resolved viral and cellular metagenomes revealed potential key virus-host interactions in a deep freshwater lake. Environ Microbiol 2019; 21:4740-4754.

42. Sedlacek CJ, McGowan B, Suwa Y, Sayavedra-Soto L, Laanbroek HJ, Stein LY, et al. A physiological and genomic comparison of Nitrosomonas cluster $6 a$ and 7 ammoniaoxidizing bacteria. Microb Ecol 2019; 78:985-94. 
43. Orellana LH, Rodriguez-R LM, Konstantinidis KT. ROCker: accurate detection and quantification of target genes in short-read metagenomic data sets by modeling slidingwindow bitscores. Nucleic Acids Res 2017; 45:e14.

44. Team RC. R: A language and environment for statistical computing. R Foundation for Statistical Computing V, Austria, 2018.

45. Wickham H. ggplot2: Elegant graphics for data analysis. New York: Springer-Verlag; 2009.

46. Alves RJE, Minh BQ, Urich T, von Haeseler A, Schleper C. Unifying the global phylogeny and environmental distribution of ammonia-oxidising archaea based on amoA genes. Nature Commun 2018; 9:1517. 